\title{
Effects of Yucca Shidigera Extract and Candida Utilis on Growth Performance and Intestinal Health of Weaned Piglets
}

\author{
Zhenguo Yang ( $\nabla$ guoguo00002@163.com ) \\ Southwest University \\ Yao Wang \\ Southwest University \\ Tianle He \\ Southwest University https://orcid.org/0000-0001-5173-589X \\ Ziema Bumbie Gifty \\ Southwest University \\ Zhihong Sun \\ Southwest University \\ Weizhong Sun \\ Southwest University \\ Zhiru Tang \\ Southwest University
}

\section{Research}

Keywords: Yucca Shidigera Extract, Candida Utilis, Occludin, $\beta$-definsin-2, Micro flora

Posted Date: November 25th, 2020

DOl: https://doi.org/10.21203/rs.3.rs-112917/v1

License: (9) This work is licensed under a Creative Commons Attribution 4.0 International License. Read Full License 


\section{Abstract}

\section{Background}

Economic benefit is an important goal pursued by animal husbandry industry. The emergence of antibiotics has promoted the development of animal husbandry, but many problems caused by the abuse of antibiotics have caused concerns about the use of antibiotics from all walks of life. Therefore, it is imperative to find alternatives to antibiotics. A large number of studies have shown that plant extracts and probiotics have certain potential in improving animal growth performance, antioxidant capacity and immune function. The purpose of this study was to explore the effects of Yucca Shidigera Extract (YSE) and Candida Utilis (CU) on weaned piglets. We compared and evaluated the effects of YSE and CU on weaned piglets from the aspects of growth performance, immunity, antioxidant function, ileal morphology and microflora changes. Forty 28-day-old healthy weaned piglets (Rongchang pig $\times$ Landrace $\times$ Large white) were randomly divided into 4 treatments: (1) control group (CON); (2) CU; (3) YSE; (4) CU+YSE.

\section{Results}

Our results showed that YSE and $\mathrm{CU}$ improved the growth performance by significantly increasing final weight, average daily gain (ADG) $(P<0.05)$, and there is decreasing trend of feed/gain ratio $(P=0.087)$. The effect of adding YSE or CU alone on growth performance had little difference, and the effect of oral CU was slightly better than that of adding YSE. At the same time, the combination of YSE and CU had a good effect on reducing the diarrhea rate. In addition, both YSE and CU increased the diversity of cecal microflora, and CU increased the diversity more significantly, but did not change the dominant microflora of cecum. We also found that the addition of YSE and CU could maintain the structural integrity of intestinal tissue and regulate intestinal $\mathrm{pH}$, to maintain the level of intestinal-associated immune proteins. At the same time, YSE and CU have certain benefits in regulating intestinal flora.

\section{Conclusion}

YSE and CU can improve the growth performance, reduce the diarrhea rate, improve intestinal health, and increase the diversity and abundance of cecal microflora in weaned piglets. Therefore, they are expected to be used as probiotics in the production of weaned piglets.

\section{Background}

Weaning piglets experienced the transformation from breast milk to solid feed, the change of living environment and the adaptation to digestive tract system. These changes are usually closely related to the proliferation of pathogens, resulting in diarrhea, poor growth performance and even death, and bring huge economic losses to animal husbandry. Therefore, the use of active ingredients in weaned piglets can protect the stability of gastrointestinal microorganisms, prevent or slow down diarrhea, improve growth performance and promote the development of alternative feed additives. With the increasing 
prohibition of antibiotics, the research on antibiotic substitutes such as probiotics, Chinese herbal medicine extracts, enzyme preparations and functional oligosaccharides is becoming more and more abundant. Plants and their extracts have attracted wide attention because of their roles in promoting animal growth, enhancing immunity, maintaining animal health and so on ${ }^{[1-4]}$. YSE is a natural plant extract, which is recognized as generally recognized as safe (GRAS), so it can be used in food, cosmetics, pharmaceutical and feed industry. YSE is used to reduce the accumulation of ammonia in feces and the concentration of ammonia in livestock and poultry. Its functions include improving growth rate, feed conversion efficiency and animal health ${ }^{[5,6]}$. In addition, many studies have shown that YSE has the functions of anti-inflammation, antioxidation, antibacterial, and immune regulation ${ }^{[7,8]}$. Probiotics have attracted wide attention because of their enhancement of animal immunity and effective defense against the invasion of pathogenic bacteria. CU is a kind of forage yeast, which is proved to be a kind of microorganism rich in cell protein, which can improve the balance of intestinal microecology and is beneficial to the growth of the host ${ }^{[9]}$. However, the research on YSE and CU in weaned piglets is insufficient, which limits their application in production. This paper explores the effects of YSE and CU on growth performance and intestinal health from a macro point of view, and preliminarily reveals their probiotic mechanism from a microscopic point of view, which provides an experimental basis for the application of YSE and CU.

\section{Methods}

\section{Experimental design, animals, and treatments}

YSE is purchased from Xi'an Lutian Biotechnology Co., Ltd. (in China), with an active ingredient content of $60 \%$. CU was purchased from German microbial strain Center (DSM 2361). Forty 28-day-old castrated weaned piglets (Rongchang pig $\times$ Landrace $\times$ Large white) with similar parity and body weight $(7.51 \pm 0.54 \mathrm{~kg})$ were randomly divided into 4 treatments with 10 replicates per treatment and 1 piglet per treatment.

\section{Experimental animal grouping, experimental design and diets}

The experiment adopted a two-factor randomized trial design and was divided into four treatment groups: (1) The control group was fed with basic diet (CON). (2) Basic diet and oral CU (1.2109 CFU / d) (CU). (3) Feed the basal diet containing YSE (200 ppm) (YSE). (4) The basal diet containing YSE (200 ppm) was fed and CU was taken orally at the same time (YSE + CU). The feeding trial period was 35 days, of which the pre-trial period was 7 days and the formal period was 28 days. The experimental diet was designed according to the standard of NRC (2012). The dietary composition and nutrition level were shown in Table 1. 
Table 1

The ingredients and nutritional compositions of diets (DM basis, \%)

\begin{tabular}{|c|c|c|c|}
\hline Ingredients & Content & \multicolumn{2}{|c|}{ Nutritional level } \\
\hline Corn & 62.8 & $\mathrm{DE}(\mathrm{MJ} / \mathrm{kg})$ & 13.81 \\
\hline Soybean meal & 19.6 & $\mathrm{CP}(\%)$ & 16.5 \\
\hline Whey powder & 6.03 & CF (\%) & 2.60 \\
\hline Fish meal & 2.30 & $\mathrm{Ca}(\%)$ & 0.73 \\
\hline Soybean oil & 0.85 & Lys (\%) & 1.27 \\
\hline Wheat Bran & 5.00 & $\mathrm{AP}(\%)$ & 0.37 \\
\hline Salt & 0.30 & $\operatorname{Thr}(\%)$ & 0.75 \\
\hline Limestone & 0.77 & Met (\%) & 0.37 \\
\hline Vitamin-mineral premix ${ }^{a}$ & 1.00 & & \\
\hline Lysine hydrochloride & 0.31 & & \\
\hline Met & 0.09 & & \\
\hline Thr & 0.09 & & \\
\hline Total & 100.0 & & \\
\hline \multicolumn{4}{|c|}{$\begin{array}{l}\text { Note: AP: available phosphorus; a Provided the following per kilogram of diet: } 13000 \mathrm{IU} \text { of vitamin A } \\
1300 \text { IU of vitamin D; } 65 \mathrm{IU} \text { of vitamin E; } 3.4 \mathrm{mg} \text { of menadione; } 37 \mathrm{mg} \text { of Pantothenic; } 6.6 \mathrm{mg} \text { of } \\
\text { Riboflavin; } 3.7 \mathrm{mg} \text { of Folic Acid; } 39 \mathrm{mg} \text { of Niacin; } 1.0 \mathrm{mg} \text { of Thiamine; } 4.3 \mathrm{mg} \text { of Vitamin B6; } 0.23 \mathrm{mg} \\
\text { Biotin; } 0.075 \mathrm{mg} \text { of Vitamin B12; } 0.43 \mathrm{~g} \text { Choline. Provided the following per kilogram of diet: } 170 \mathrm{mg} \\
\text { Zn; } 140 \mathrm{mg} \text { Fe; } 34 \mathrm{mg} \mathrm{Mn} ; 16 \mathrm{mg} \text { Cu; } 0.29 \mathrm{mg} \text { I; } 0.29 \mathrm{mg} \text { Se. In addition to digestive energy data, the } \\
\text { remaining nutrients are measured values. }\end{array}$} \\
\hline
\end{tabular}

\section{Feeding and management}

The experiment was carried out in the farm of the College of Animal Science and Technology of Southwest University (Chongqing, China). All piglets were fed at 08:00, 12:00 and 18:00, respectively, and drank freely. The remaining feed in the trough was weighed before feeding on the second day. At 8 am on the first day of the trial, piglets were weighed as the initial weight, and at 8 am on the 29 th day as the final weight.

\section{Sample collection and treatment}

On the $\mathrm{d} 29$ of the formal stage, 6 weaned piglets with similar average body weight were randomly selected in each group, and blood samples were collected from the anterior vena cava for $10 \mathrm{~mL}$ with an anticoagulant tube containing heparin sodium. All blood samples were centrifuged at $4{ }^{\circ} \mathrm{C}$ for $4000 \mathrm{r} /$ min. After $20 \mathrm{~min}$, the supernatant was separated and stored at $-20^{\circ} \mathrm{C}$, which was used to detect the antioxidation index of plasma. The animals were slaughtered after intravenous anesthesia with 
pentobarbital sodium (50 mg/kg·Bw). After the animals stopped breathing, cut open the chest and abdominal cavity, and removed the internal organs. The weights of liver, heart, spleen, thymus, pancreas, kidney and mesenteric lymph nodes were measured accurately, and a $3 \mathrm{~cm}$ length intestinal tissue ligated in the middle ileum was collected and placed with a $50 \mathrm{~mL}$ centrifuge tube containing tissue fixation solution for tissue section production. The contents of jejunum, ileum and cecum were collected and placed on ice in a small sealed pocket for the separation of microorganisms. The contents of $2 \mathrm{~mL}$ cecum were collected in a $2 \mathrm{~mL}$ centrifuge tube to extract DNA, for intestinal microflora analysis. The jejunum and ileum of $10 \mathrm{~cm}$ were collected and rinsed with precooled saline, then the mucous membrane was scraped with glass slides and stored at $-80^{\circ} \mathrm{C}$ for Western blotting analysis. The $\mathrm{pH}$ value of gastrointestinal contents and urine were measured by pH meter (METTLER TOLEDO, S220, Switzerland).

\section{Determination of growth performance}

The calculation formula of growth performance is as follows:

Average daily gain $(A D G)=$ whole period weight gain $(g) /$ days $(d)$.

Average daily feed intake $(A D F I)=$ whole period feed intake $(g) /$ days $(d)$.

Feed conversion rate = average daily gain $(\mathrm{g}) /$ average daily feed intake $(\mathrm{g})$.

\section{Determination of diarrhea rate}

In the experiment, the total number of diarrhea in each group of piglets was recorded every day, and the number of watery diarrhea was recorded separately, and the incidence of diarrhea was calculated. Among them, the incidence of diarrhea $(\%)=$ the number of diarrhea $\times$ days (number of piglets $\times$ days of trial) $\times$ $100 \%$.

\section{Determination of organ index}

The organ index is calculated by the following formula:

Organ index $(\mathrm{g} / \mathrm{kg})=$ organ wet weight $(\mathrm{g}) /$ pig live weight $(\mathrm{kg})$

Determination of biochemical Indexes in Plasma

The activities or contents of total antioxidant capacity (T-AOC), total superoxide dismutase (T-SOD), catalase (CAT), malondialdehyde (MDA), total cholesterol (T-CHO), acetylcholinesterase (A-CHE), blood urea nitrogen (BUN), uric acid (UA), glucose (GLU), serum Alanine transaminase (ALT) and Aspartate aminotransferase (AST) in plasma and liver were measured by spectrophotometer. The kits were purchased from Nanjing JianCheng Biology Research Institute, China, and the operation steps were carried out according to the instructions.

\section{Intestinal mucosal morphology}


The brief procedure for the morphological determination of intestinal mucosa was as follows: the intestinal mucosal samples were taken from the fixed solution, dehydrated with ethanol, transparent with xylene and embedded in paraffin. $5 \mathrm{~mm}$ thick sections were made and observed under microscope after hematoxylin-eosin (H.E.) staining. The mucosal morphological indexes such as villus height and villus width were measured by OPTPro image processing software; the films were read by double blind method, and 5 visual fields were taken from each slice for observation. Villous Height $(\mathrm{VH})$ is the vertical distance from the top of the villi to the opening of the crypt. Crypt Depth (CD) is the vertical distance from the opening of the crypt to the base of the crypt. Ratio of villus height to crypt depth (V/C).

\section{Levels of $\beta$-defensin- 2 and tight junction protein in intestinal mucosa}

Jejunal and ileal mucosa of piglets were selected to detect the level of intestinal mucosal protein. The indexes measured were $\beta$-defensin- 2 and tight junction protein (Occludin). The reagents needed during the test (protein lysate, separation gel, concentrated gel, protein electrophoresis buffer, etc.) were prepared by the laboratory.

\section{Intestinal microflora}

The contents of cecum were selected for DNA extraction, and the extraction steps were referred to the extraction method of Power Fecal DNA Isolation Kit, which was purchased from Shenzhen Anbisheng Technology Co., Ltd, China. The extracted DNA was detected by agarose gel electrophoresis, and the qualified DNA was sent to Chongqing inventory Biotechnology Co., Ltd for microbial second generation sequencing. The main processes include: DNA extraction and detection $\rightarrow$ Design primers with special bar code for V4 variable region $\rightarrow$ PCR amplification and purification $\rightarrow$ Product homogenization $\rightarrow$ Miseq PE library construction $\rightarrow$ Meseq high throughput sequencing.

\section{Test data processing}

All of the data were first processed with Excel (Microsoft 2020), and then statistically analyzed with SPSS analysis of variance (IBM 26.0). The results are expressed in the form of average and average standard error (SEM). $P<0.05$ indicated that the difference was significant.

\section{Results And Analysis}

\section{Effects of YSE and CU on growth performance of weaned piglets}

The effects of oral YSE and CU on the growth performance of weaned piglets were shown in Table 2. There was no significant difference in initial weight among groups $(P>0.05)$. The interaction between YSE and CU was not significant in terms of final weight, average daily gain and average daily feed intake $(P>0.05)$, and there was a significant trend in the interaction effect on the feed / gain ratio ratio $(P=$ $0.057)$. YSE significantly increases the final weight and average daily gain of weaned piglets $(P<0.05)$, 
and had a tendency to reduce the feed-to-meat ratio $(P=0.087)$, and had no significant effect on daily feed intake $(P>0.05)$. CU significantly increased the final weight, average daily gain, and average daily feed intake of weaned piglets $(P<0.05)$, and the effect of feed-to-meat ratio was not significant $(P>0.05)$. The addition of YSE or CU had little effect on the diarrhea rate of weaned piglets, but the mixed use of YSE and CU reduced the diarrhea rate of weaned piglets by $28 \%$.

Table 2

Effects of YSE and CU on growth performance in weaned piglets

\begin{tabular}{|c|c|c|c|c|c|c|c|c|}
\hline \multirow[t]{2}{*}{ Items } & \multicolumn{4}{|c|}{ Treatments } & \multirow[t]{2}{*}{ SEM } & \multicolumn{3}{|c|}{$P$-value } \\
\hline & CON & $\mathrm{CU}$ & YSE & $\begin{array}{l}\text { CU+ } \\
\text { YSE }\end{array}$ & & YSE & $\mathrm{CU}$ & $\begin{array}{l}\text { CU+ } \\
\text { YSE }\end{array}$ \\
\hline Initial weight (kg) & 7.69 & 7.55 & 7.62 & 7.76 & 0.12 & 0.563 & 0.991 & 0.253 \\
\hline Final weight (kg) & 14.6 & 15.8 & 15.6 & 16.2 & 0.32 & 0.037 & 0.013 & 0.357 \\
\hline Average daily gain $(\mathrm{g} / \mathrm{d})$ & 247 & 294 & 286 & 300 & 9.43 & 0.023 & 0.003 & 0.104 \\
\hline $\begin{array}{l}\text { Average daily feed intake } \\
(\mathrm{g} / \mathrm{d})\end{array}$ & 471 & 516 & 484 & 530 & 13.1 & 0.292 & 0.002 & 0.989 \\
\hline Feed/Gain(g/g) & 1.91 & 1.76 & 1.71 & 1.77 & 0.05 & 0.087 & 0.459 & 0.057 \\
\hline Diarrhea rate & 0.179 & 0.169 & 0.161 & 0.129 & - & - & - & - \\
\hline Mortality & 0.2 & 0.1 & 0.1 & 0 & - & - & - & - \\
\hline \multicolumn{9}{|c|}{$\begin{array}{l}\text { Note: } C O N \text { is the control group, } C U \text { is } C U \text { group, YSE is YSE group, } C U+Y S E \text { is the mixture of } C U \text { and } \\
\text { YSE. } P<0.05 \text { means the difference is significant, } P>0.05 \text { means the difference is not significant. The } \\
\text { same below. }\end{array}$} \\
\hline
\end{tabular}

\section{Effects of YSE and CU on organ indexs of weaned piglets}

As shown in Table 3, the interaction between YSE and CU on spleen index and lymph node index was significant $(P<0.05)$, liver index had a significant trend $(P<0.05)$, but the interaction effect of other organ indexes was not significant $(P>0.05)$. The addition of YSE to the diet significantly increased the spleen index and lymph node index $(P<0.05)$, and had a significant tendency to increase the pancreatic index ( $P$ $=0.07)$. Oral CU tended to increase spleen index $(P=0.05)$ and lymph node index $(P=0.08)$, but had no significant effect on other organ index $(P>0.05)$. 
Table 3

Effects of YSE group and CU on organ indexes in weaned piglets $(\mathrm{g} / \mathrm{kg})$

\begin{tabular}{|c|c|c|c|c|c|c|c|c|}
\hline \multirow[t]{2}{*}{ Items } & \multicolumn{4}{|c|}{ Treatments } & \multirow[t]{2}{*}{ SEM } & \multicolumn{3}{|c|}{$P$-value } \\
\hline & CON & $\mathrm{CU}$ & YSE & $\begin{array}{l}\text { CU+ } \\
\text { YSE }\end{array}$ & & YSE & $\mathrm{CU}$ & $\begin{array}{l}\text { CU+ } \\
\text { YSE }\end{array}$ \\
\hline Cardiac index & 4.37 & 4.19 & 4.04 & 4.45 & 0.42 & 0.93 & 0.78 & 0.49 \\
\hline Liver index & 25.6 & 24.9 & 26.3 & 27.2 & 1.95 & 0.55 & 0.29 & 0.06 \\
\hline Thymus index & 0.42 & 0.63 & 0.51 & 0.54 & 0.13 & 0.86 & 0.38 & 0.52 \\
\hline Kidney index & 5.26 & 5.79 & 5.55 & 6.14 & 0.31 & 0.32 & 0.86 & 0.12 \\
\hline spleen index & 1.68 & 1.95 & 2.06 & 2.96 & 0.21 & $\begin{array}{l}< \\
0.05\end{array}$ & 0.05 & 0.005 \\
\hline Pancreas index & 1.16 & 1.29 & 1.57 & 1.48 & 0.15 & 0.07 & 0.88 & 0.50 \\
\hline $\begin{array}{l}\text { Mesenteric lymph nodes } \\
\text { index }\end{array}$ & 1.38 & 1.79 & 2.35 & 2.84 & 0.12 & $<.05$ & 0.08 & 0.03 \\
\hline
\end{tabular}

\section{Effects of YSE and CU on gastrointestinal pH of weaned piglets}

As shown in Table 4, the interaction between $\mathrm{CU}$ and $\mathrm{YSE}$ on gastric $\mathrm{pH}$, ileal $\mathrm{pH}$, cecal $\mathrm{pH}$ and urine $\mathrm{pH}$ was significant $(P<0.05)$, but the interaction of other indexes was not significant $(P>0.05)$. YSE significantly reduced gastric $\mathrm{pH}$, rectal $\mathrm{pH}$ and urine $\mathrm{pH}(P<0.05)$, and had a significant tendency to lower colon $\mathrm{pH}(P=0.09)$, but had no significant effect on jejunum $\mathrm{pH}$, ileum $\mathrm{pH}$, and cecal $\mathrm{pH}(P>0.05)$. CU significantly reduced urine $\mathrm{pH}(\mathrm{P}<0.05)$, but had no significant effect on stomach $\mathrm{pH}$, jejunum $\mathrm{pH}$, ileum $\mathrm{pH}$, colon $\mathrm{pH}$, cecal $\mathrm{pH}$, and rectal $\mathrm{pH}(P>0.05)$.

Table 4

Effects of YSE and $\mathrm{CU}$ on $\mathrm{pH}$ of gastrointestinal tract in weaned piglets

\begin{tabular}{|c|c|c|c|c|c|c|c|c|}
\hline \multirow[t]{2}{*}{ Items } & \multicolumn{4}{|c|}{ Treatments } & \multirow[t]{2}{*}{ SEM } & \multicolumn{3}{|c|}{$P$-value } \\
\hline & CON & $\mathrm{CU}$ & YSE & CU+YSE & & YSE & CU & CU+YSE \\
\hline Stomach pH-value & 3.37 & 4.40 & 2.93 & 2.85 & 0.42 & 0.03 & 0.28 & 0.01 \\
\hline Jejunum pH-value & 5.71 & 5.86 & 5.73 & 5.39 & 0.32 & 0.49 & 0.77 & 0.46 \\
\hline Ileum pH-value & 6.28 & 6.70 & 6.51 & 5.96 & 0.21 & 0.24 & 0.76 & 0.04 \\
\hline Colon $\mathrm{pH}$-value & 6.17 & 6.12 & 5.71 & 5.85 & 0.20 & 0.09 & 0.84 & 0.66 \\
\hline Cecum pH-value & 5.84 & 6.11 & 6.00 & 5.80 & 0.17 & 0.65 & 0.85 & 0.19 \\
\hline Rectum pH-value & 6.32 & 6.92 & 6.02 & 5.80 & 0.16 & $<0.01$ & 0.25 & 0.02 \\
\hline Urine $\mathrm{pH}$-value & 7.36 & 6.66 & 6.44 & 6.32 & 0.13 & 0.05 & 0.03 & 0.06 \\
\hline
\end{tabular}




\section{Effects of YSE and CU on Plasma biochemical Indexes of weaned piglets}

As shown in Table 5, oral CU and YSE have significant interaction effects on GLU, AST activity, UA, T-SOD, T-AOC, and MDA $(P<0.05)$, and on BUN had significant trend $(P=0.06)$, the interaction effect on other indicators was not significant $(P>0.05)$. Dietary supplementation of YSE significantly increased plasma GLU, BUN, UA, T-SOD, CAT $(P<0.05)$, and significantly decreased T-CHO content, AST, BUN, MDA and blood serum amylase (AMS) $(P<0.05)$, but had no significant effect on acetylcholinesterase activity. Oral CU significantly decreased plasma GLU, ALT, UA, MDA levels and amylase activity, significantly increased AST, T-SOD, T-AOC and CAT activity $(P<0.05)$, but had no significant effect on BUN, T-CHO and A-CHE $(P$ $<0.05)$.

Table 5

Effects of YSE and CU on plasma parameters in weaned piglets

\begin{tabular}{|c|c|c|c|c|c|c|c|c|}
\hline \multirow[t]{2}{*}{ Items } & \multicolumn{4}{|c|}{ Treatments } & \multirow[t]{2}{*}{ SEM } & \multicolumn{3}{|c|}{$P$-value } \\
\hline & CON & CU & YSE & $\begin{array}{l}\text { CU+ } \\
\text { YSE }\end{array}$ & & YSE & $\mathrm{CU}$ & $\begin{array}{l}\text { CU+ } \\
\text { YSE }\end{array}$ \\
\hline $\mathrm{GLU}(\mathrm{mmol} / \mathrm{L})$ & 5.19 & 5.52 & 4.78 & 5.06 & 0.23 & 0.05 & 0.54 & 0.21 \\
\hline $\mathrm{T}-\mathrm{CHO}(\mathrm{mmol} / \mathrm{L})$ & 2.27 & 2.12 & 2.07 & 2.06 & 0.16 & 0.15 & 0.23 & 0.75 \\
\hline AST(U/L) & 28.5 & 28.9 & 27.3 & 25.4 & 1.69 & 0.25 & 0.32 & 0.18 \\
\hline $\operatorname{ALT}(\mathrm{U} / \mathrm{L})$ & 26.3 & 25.1 & 24.6 & 25.7 & 1.78 & 0.11 & 0.44 & 0.90 \\
\hline BUN (mmol/L) & 4.73 & 4.54 & 3.15 & 3.77 & 0.20 & $<.001$ & 0.30 & 0.06 \\
\hline $\begin{array}{l}\text { T-SOD } \\
\text { (U/mgprot) }\end{array}$ & 30.9 & 49.5 & 47.3 & 55.3 & 2.41 & $<0.001$ & 0.04 & $<0.01$ \\
\hline T-AOC $(\mathrm{U} / \mathrm{mL})$ & 1.84 & 2.00 & 2.84 & 3.42 & 0.10 & $<0.01$ & $\begin{array}{l}<.01 \\
0.01\end{array}$ & $<0.01$ \\
\hline MDA (nmol/L) & 8.31 & 3.79 & 4.35 & 1.30 & 0.75 & 0.02 & 0.01 & 0.01 \\
\hline CAT $(\mathrm{U} / \mathrm{mL})$ & 4.47 & 8.47 & 13.6 & 16.8 & 0.53 & $<0.01$ & $\stackrel{<}{<.01}$ & 0.01 \\
\hline $\mathrm{A}-\mathrm{CHE}(\mathrm{U} / \mathrm{mL})$ & 7.74 & 8.78 & 8.93 & 9.09 & 0.44 & 0.19 & 0.28 & 0.43 \\
\hline
\end{tabular}

\section{Effects of YSE and CU on the morphology and structure of ileal mucosa in weaned piglets}

As shown in Fig. 1, the structure of ileal villi of piglets in the control group was incomplete, there was shedding linearity, and the villi were sparsely arranged, so it was known that weaning stress and feed 
transformation did damage the intestinal structure of weaned piglets, even after one month of weaning. Intestinal morphology and structure wasn't fully recovered, but the development of ileal villus structure of the three experimental groups was better than that of the control group, and the mucosal development was improved in varying degrees.

As shown in Table 6, the interaction between YSE and CU was significant in villus height / crypt depth ( $P$ $<0.01)$, but not in villus height and crypt depth $(P>0.05)$. YSE significantly increased ileal villus height, villus height / crypt depth $(P<0.05)$, and significantly decreased crypt depth $(P<0.05)$. Oral administration of CU significantly increased ileal villus height, villus height / crypt depth $(P<0.05)$, tended to increase villus height $(P<0.10)$, and significantly decreased crypt depth $(P<0.05)$.

Table 6

Effects of YSE and CU on morphology of ileum in weaned piglets

\begin{tabular}{|c|c|c|c|c|c|c|c|c|}
\hline \multirow[t]{2}{*}{ Items } & \multicolumn{4}{|c|}{ Treatments } & \multirow[t]{2}{*}{ SEM } & \multicolumn{3}{|c|}{$P$-value } \\
\hline & CON & CU & YSE & $\begin{array}{l}\text { CU+ } \\
\text { YSE }\end{array}$ & & YSE & CU & $\begin{array}{l}\text { CU+ } \\
\text { YSE }\end{array}$ \\
\hline Villus height $(\mu \mathrm{m})$ & 471 & 484 & 497 & 516 & 9.42 & 0.01 & 0.10 & 0.80 \\
\hline Crypt depth $(\mu \mathrm{m})$ & 274 & 256 & 266 & 230 & 7.82 & 0.05 & 0.004 & 0.27 \\
\hline $\begin{array}{l}\text { Vilius height/crypt } \\
\text { depth }\end{array}$ & 1.72 & 1.89 & 1.87 & 2.25 & 0.04 & 0.001 & $<0.001$ & 0.03 \\
\hline
\end{tabular}

\section{Effects of YSE and CU on the levels of $\beta$-definsin-2 and Occludin in intestinal mucosa of weaned piglets}

Table 7 showed that the interaction between YSE and CU was significant at the levels of Occludin and $\beta$ definsin-2 in jejunal mucosa $(P<0.05)$, but not at the level of $\beta$-definsin- 2 and $\beta$-definsin-2 in jejunal mucosa $(P>0.05)$. Dietary supplementation of YSE significantly increased jejunal Occludin $(P<0.05), \beta-$ definsin-2 and ileal Occludin levels, but had no significant effect on ileal $\beta$-definsin-2 levels $(P>0.05)$. Oral administration of $\mathrm{CU}$ significantly increased the levels of Occludin and $\beta$-definsin-2 in jejunum $(P<0.05)$, but had no significant effect on the levels of Occludin and $\beta$-definsin-2 in ileal mucosa $(P>0.05)$. 
Table 7

The effect of YSE and CU on level of intestinal mucosa $\beta$-definsin-2 and Occludin

\begin{tabular}{|c|c|c|c|c|c|c|c|c|}
\hline \multirow[t]{2}{*}{ Items } & \multicolumn{4}{|c|}{ Treatments } & \multirow[t]{2}{*}{ SEM } & \multicolumn{3}{|c|}{$P$-value } \\
\hline & CON & $\mathrm{CU}$ & YSE & CU+YSE & & YSE & $\mathrm{CU}$ & CU+YSE \\
\hline \multicolumn{9}{|l|}{ Jejunum } \\
\hline Occludin & 0.34 & 0.43 & 0.57 & 0.76 & 0.03 & $<0.01$ & $<0.01$ & 0.10 \\
\hline$\beta$-definsin-2 & 0.89 & 1.04 & 1.07 & 1.31 & 0.09 & 0.02 & 0.04 & 0.63 \\
\hline \multicolumn{9}{|l|}{ Ileum } \\
\hline Occludin & 0.69 & 0.82 & 0.97 & 0.94 & 0.05 & $<0.01$ & 0.15 & $<0.01$ \\
\hline$\beta$-definsin-2 & 1.10 & 1.29 & $1 . .33$ & 1.38 & 0.11 & 0.27 & 0.49 & 0.32 \\
\hline
\end{tabular}

\section{Effects of YSE and CU on cecal microflora of weaned piglets}

\section{Dilution curve}

As shown in the Fig. 3, the number of species or diversity of each group of samples increases with the increase of the number of sequences. The curves of Shannon index and Chao1 index tended to be flat. The Observed species curve still had an upward trend, but the trend slowed down significantly. The curve height of the control group was lower than that of the three experimental group.

\section{An overview of cecal microflora}

A total of 688961 sequences were obtained from 12 samples in 4 groups by Miseq sequencing. After removing the low quality sequence, the sequence number was 566122 and the average length was 308 bp. The 566122 sequences were clustered into 3498 OTU. These bacteria were divided into 21 phyla, 38 classes, 72 orders, 116 families, 294genera and 305species. According to the Venn diagram (Fig. 4), the total number of OTU in the four groups was 955 . There were 1969 OTU, -specific OTU in the control group, 2217 OTU, -specific OTU in the CU group, 2146 OTU, -specific OTU in the YSE group, and 2242 OTU, -specific 319 in the control group. It was known that the number of bacteria in the control group was the least, followed by YSE group, CU group, and the most was CU + YSE group.

\section{Composition of cecal microflora}

As shown in Fig. 5 that the microorganisms in the cecum of weaned piglets at the gate level were composed of Bacteroidetes, Firmicutes, Proteobacteria, Actinobacteria, Spirochaetae, Verrucomicrobia and so on. Among them, Bacteroidetes, Firmicutes and Proteobacteria were the dominant microflora in the cecum of weaned piglets, and the proportion was more than $95 \%$. At the class level, the bacteria that 
make up the cecal microflora include Bacteroidetes, Clostridia, Alphaproteobacteria, Negativicutes, Actinobacteria, Erysipelotrichia, Cytophagia and so on. The genus level is mainly composed of Prevotellaceae, Leeia, Campylobacter, Succinivibrio, Clostridium sensu stricto 1, Bacteroides, Anaerovibrio, Roseburia, Lactobacillus, Ruminococcaceae and so on.

Table 8 showed that YSE and CU had certain effects on the structure of cecal microflora of weaned piglets $(P<0.05)$. Dietary supplementation of YSE significantly decreased the relative abundance of acidobacteria bacteria in cecum of weaned piglets $(P<0.05)$, the bacteria of Spirochaetae had an increasing trend $(P=0.072)$. However, it had no significant effect on the relative abundance of Bacteroides, Firmicutes, Proteobacteria, Actinobacteria, Verrucomicrobia, Tenericutes, Lentisphaerae ( $\mathrm{P}$ > 0.05). Oral administration of CU significantly decreased the relative abundance of Proteobacteria and Actinobacteria $(P<0.05)$, and significantly increased the relative abundance of Verrucomicrobia microbacteria. It had no significant effects on the relative abundance of Bacteroides, Firmicutes, Spirochaetae, Tenericutes, Lentisphaerae and Acidobacteria $(P>0.05)$. YSE and CU had a significant interaction effect on the relative abundance of Proteus bacteria, and synergistically decreased the relative abundance of Proteus bacteria $(P<0.05)$.

Table 8

Composition of caecum micro flora at phylum level

\begin{tabular}{|lllllllll|}
\hline Items & \multicolumn{3}{l}{ Treatments } & \multicolumn{7}{c}{ SEM } & \multicolumn{2}{l}{ P-value } \\
\cline { 2 - 3 } & CON & CU & YSE & CU+YSE & & YSE & CU & CU+YSE \\
\hline Bacteroides & 59.5 & 61.6 & 60.2 & 68.1 & 4.75 & 0.456 & 0.354 & 0.605 \\
\hline Firmicutes & 26.2 & 24.3 & 20.0 & 21.8 & 3.78 & 0.283 & 0.988 & 0.638 \\
\hline Proteobacteria & 11.2 & 10.9 & 15.5 & 6.40 & 1.31 & 0.947 & 0.007 & 0.01 \\
\hline Actinobacteria & 2.30 & 1.05 & 1.22 & 1.05 & 0.32 & 0.126 & 0.055 & 0.126 \\
\hline Spirochaetae & 0.07 & 0.43 & 2.20 & 0.60 & 0.55 & 0.072 & 0.295 & 0.115 \\
\hline Verrucomicrobia & 0.04 & 0.94 & 0.06 & 1.43 & 0.14 & 0.117 & $<0.001$ & 0.137 \\
\hline Tenericutes & 0.03 & 0.11 & 0.12 & 0.11 & 0.03 & 0.19 & 0.317 & 0.189 \\
\hline Lentisphaerae & 0.03 & 0.03 & 0.01 & 0.30 & 0.14 & 0.343 & 0.28 & 0.363 \\
\hline Acidobacteria & 0.07 & 0.06 & 0.03 & 0.04 & 0.01 & 0.024 & 0.593 & 0.23 \\
\hline
\end{tabular}

Table 9 showed that the relative abundance of bacteria at the cecal microflora level of weaned piglets. Dietary supplementation of YSE significantly increased the relative abundance of Bacteroides in cecum of weaned piglets $(P<0.05)$, and significantly decreased the relative abundance of Clostridiaceae, Veillonellaceae, Erysipelotrichaceae, Acidaminococcaceae, Streptococcaceae, Campylobacteraceae, and Streptomycetaceae in weaned piglets $(P<0.05)$. It had no significant effect on the relative abundance of bacteria in Prevotellaceae, Porphyromonadaceae, Rikenellaceae, Cytophagaceae, Ruminococcaceae, Lactobacillaceae and so on $(P>0.05)$. Oral administration of $\mathrm{CU}$ significantly increased the relative 
abundance of Bacteroidales, Lachnospiraceae and Ruminococcaceae $(P<0.05)$, and significantly decreased the relative abundance of Clostridiaceae, Streptococcaceae, Enterobacteriaceae and Streptomycetaceae $(P<0.05)$. It had no significant effect on the relative abundance of bacteria in Prevotellaceae, Porphyromonadaceae, Rikenellaceae and Cytophagaceae $(P>0.05)$. YSE and CU had significant interaction effects on the relative abundance of Bacteroidales, Lachnospiraceae, Erysipelotrichaceae, Streptococcaceae, Campylobacteraceae, Enterobacteriaceae, Succinivibrionaceae and Streptomycetaceae $(P<0.05)$. 
Table 9

Composition of caecum micro flora at family level

\begin{tabular}{|c|c|c|c|c|c|c|c|c|}
\hline \multirow[t]{2}{*}{ Items } & \multicolumn{4}{|c|}{ Treatments } & \multirow[t]{2}{*}{ SEM } & \multicolumn{3}{|c|}{$P$-value } \\
\hline & CON & CU & YSE & CU+YSE & & YSE & CU & $C U+Y S E$ \\
\hline Prevotellaceae & 47.4 & 48.6 & 51.4 & 46 & 3.74 & 0.888 & 0.511 & 0.327 \\
\hline Bacteroidales & 8.81 & 8.61 & 5.65 & 19.8 & 1.09 & 0.006 & $<0.001$ & $<0.001$ \\
\hline Porphyromonadaceae & 0.72 & 0.90 & 0.89 & 0.89 & 0.18 & 0.479 & 0.228 & 0.689 \\
\hline Rikenellaceae & 1.81 & 1.24 & 1.41 & 1.00 & 0.19 & 0.372 & 0.100 & 0.295 \\
\hline Cytophagaceae & 0.15 & 0.17 & 0.13 & 0.14 & 0.02 & 0.396 & 0.470 & 0.739 \\
\hline Lachnospiraceae & 6.09 & 10.3 & 7.84 & 8.11 & 0.67 & 0.746 & 0.010 & 0.018 \\
\hline Ruminococcaceae & 4.90 & 6.46 & 5.42 & 7.37 & 0.61 & 0.738 & 0.006 & 0.287 \\
\hline Clostridiaceae & 2.00 & 1.09 & 1.34 & 0.75 & 0.22 & 0.049 & 0.008 & 0.485 \\
\hline Veillonellaceae & 4.76 & 2.48 & 1.43 & 1.63 & 0.50 & 0.001 & 0.311 & 0.177 \\
\hline Erysipelotrichaceae & 1.78 & 0.51 & 0.55 & 0.32 & 0.13 & 0.001 & $<0.001$ & 0.004 \\
\hline Lactobacillaceae & 1.36 & 1.15 & 1.05 & 1.27 & 0.11 & 0.425 & 0.972 & 0.099 \\
\hline Peptostreptococcaceae & 0.66 & 0.54 & 0.74 & 0.50 & 0.09 & 0.771 & 0.079 & 0.559 \\
\hline Acidaminococcaceae & 0.42 & 0.40 & 0.28 & 0.30 & 0.04 & 0.028 & 0.943 & 0.794 \\
\hline Streptococcaceae & 0.23 & 0.04 & 0.05 & 0.04 & 0.03 & 0.030 & 0.009 & 0.020 \\
\hline Neisseriaceae & 0.76 & 0.63 & 0.68 & 0.62 & 0.11 & 0.683 & 0.439 & 0.756 \\
\hline Campylobacteraceae & 0.44 & 0.25 & 0.13 & 0.17 & 0.05 & 0.003 & 0.156 & 0.039 \\
\hline Enterobacteriaceae & 0.65 & 0.13 & 0.30 & 0.54 & 0.05 & 0.508 & 0.014 & $<0.001$ \\
\hline Succinivibrionaceae & 0.48 & 1.22 & 1.56 & 0.18 & 0.16 & 0.897 & 0.084 & $<0.001$ \\
\hline Alcaligenaceae & 0.21 & 0.17 & 0.19 & 0.14 & 0.04 & 0.560 & 0.330 & 0.917 \\
\hline Comamonadaceae & 0.16 & 0.13 & 0.14 & 0.12 & 0.02 & 0.297 & 0.095 & 0.892 \\
\hline Streptomycetaceae & 0.65 & 0.40 & 0.44 & 0.43 & 0.04 & 0.042 & 0.010 & 0.043 \\
\hline
\end{tabular}

\section{Alpha diversity analysis}

It can be seen from Fig. 7 that dietary supplementation of YSE and CU had significant effects on alpha diversity of cecal microflora of weaned piglets $(P<0.05)$. The diversity index box chart of the test group was higher than that of the control group, indicated that the alpha diversity of the test group was higher than that of the control group. 
Table 10 showed that compared with the control group, the Observed species, Chao1 and Fisher indexes of YSE group, CU group and mixed group were significantly higher than those of the control group $(P<$ 0.05). The Shannon index in the YSE group and CU group was significantly higher than that in the control group $(P<0.05)$, but there was no significant difference between the mixed group and the control group $(P>0.05)$. There was no significant difference in PD index between $\mathrm{CU}$ group and mixed group $(P>0.05)$, but it was significantly higher than that in YSE group and control group $(P<0.05)$, and that in YSE group was significantly higher than that in control group $(P<0.05)$.

Table 10

Alpha diversity analysis

\begin{tabular}{|llllllllll|}
\hline Items & \multicolumn{3}{l}{ Treatments } & \multicolumn{7}{c}{ SEM } & \multicolumn{2}{c|}{$\boldsymbol{P}$-Value } \\
\cline { 2 - 3 } & CON & CU & YSE & CU+YSE & & YSE & CU & CU+YSE \\
\hline observed & 1003 & 1251 & 1197 & 1231 & 39.5 & 0.058 & 0.007 & 0.026 \\
\hline chao1 & 1356 & 1735 & 1698 & 1737 & 61.2 & 0.023 & 0.009 & 0.024 \\
\hline shannon & 4.91 & 5.54 & 5.29 & 5.17 & 0.11 & 0.967 & 0.059 & 0.011 \\
\hline simpson & 0.95 & 0.98 & 0.97 & 0.96 & 0.01 & 0.86 & 0.729 & 0.146 \\
\hline fisher & 258 & 365 & 344 & 357 & 8.44 & 0.002 & $<0.001$ & 0.001 \\
\hline Pd & 80.0 & 90.0 & 86.1 & 90.3 & 0.88 & 0.008 & $<0.001$ & 0.011 \\
\hline
\end{tabular}

\section{Beta diversity analysis}

Principal Co-ordinates Analysis is a non-constrained data dimensionality reduction analysis method, which can be used to study the differences of sample community composition, and is a common method to analyze Beta diversity. UniFrac is a Beta diversity index based on phylogenetic relationships, and it is one of the most commonly used methods to analyze the distance between microbial communities. The commonly used sample distance indicators based on species data include Bray-Curtis and Jaccord, etc. Bray-Curtis considers species abundance, while Jaccord is based on binary data (species existence is marked as 1 , non-existence is marked as 0 ). The smaller the distance between samples, the smaller the difference between communities. As can be seen from Fig. 8, the distance of CU group, YSE group and $\mathrm{CU}+$ YSE group in the figure is relatively close, while that of the control group is far away, indicating that the difference of microbial community among the three test groups is less than that between the control group.

\section{Discussion}

\section{Effects of CU and YSE on growth performance of weaned piglets}


$\mathrm{CU}$ is a kind of yeast with the characteristics of general yeast. Our results showed that CU had a positive effect on the growth performance of weaned piglets. At present, there are few studies on the application of $\mathrm{CU}$ in pigs. Oral active yeast preparation for early weaned piglets can help to relieve diarrhea, promote piglet growth, improve survival rate and growth performance ${ }^{[10]}$. Active yeast preparation can promote the growth performance and enhance the immune function of piglets, and the mechanism of action may be related to the main components of cell wall, $\beta$-glucan, phosphorylated oligosaccharides and intracellular active peptides ${ }^{[11-12]}$. In this study, we fed CU together with its fermentation medium to piglets. Nucleotides, amino acids, peptides and other flavor substances in yeast culture were important factors to improve the feed intake of piglets. Shen et al. ${ }^{[13]}$ showed that yeast culture could significantly increase the feed intake of piglets. In addition, the researches on piglets and growing-finishing pigs showed that yeast culture could improve the daily gain and feed utilization rate of piglets ${ }^{[14-16]}$. It may be that yeast culture stimulated intestinal fermentation, increased the yield of volatile fatty acids and the end products of bacterial fermentation, and provided some energy for pigs to improve nutrient utilization $^{[17-19]}$.

The improvement of YSE on the growth performance of pigs is attributed to the fact that YSE saponins reduce the concentration of ammonia and provide a good environment for digestion and absorption of nutrients. It is also the result of antioxidant and anti-inflammatory effects of YSE polyphenols. The health of animals was maintained at a good level, and the energy loss caused by disease was reduced ${ }^{[20,21]}$. In comparison, the results of Van, Colina and others were different. The results of these scholars showed that YSE reduced the concentration of ammonia in livestock barn or the content of ammonia nitrogen in feces, but had no significant effect on growth performance ${ }^{[22,23]}$. This may be caused by different feed formula, environment, adding amount, physiological stage of pig and so on. The feed composition, especially the content of crude protein, may affect the effect of YSE. Ma et al added YSE to the diets of finishing pigs with crude protein content of $16 \%$ and $14 \%$ respectively, and the ammonia concentration in the barn was significantly different ${ }^{[24]}$. Colina et al. ${ }^{[23]}$ showed that the optimum addition amount of YSE in weaned piglets was about $120 \mathrm{ppm}$, and the ammonia emission and growth performance were ideal ${ }^{[12]}$. In this study, the addition amount of YSE was 200 ppm, and the actual active ingredient is $120 \mathrm{ppm}$. The addition amount of YSE in pig diets was different in different physiological stages. Generally speaking, the addition amount of YSE was 50-200 ppm. The diarrhea rate of piglets in the mixed group of CU and YSE was $12.9 \%$, which was $27.9 \%$ lower than that of the control group, indicating that the mixed use of $\mathrm{CU}$ and YSE had a certain effect on reducing diarrhea in piglets.

\section{Effects of CU and YSE on Organ Index of weaned piglets}

With the growth of animals, the visceral organs of animals gradually increase in weight and volume, and their functions tend to be improved, so the organ index can reflect the functional status of animals to a certain extent ${ }^{[25]}$. Our results showed that oral CU did not affect the organ development of weaned piglets, but had a tendency to promote the development of spleen and mesenteric lymph nodes, and the addition of YSE in diet did not affect the development of heart, liver, thymus and kidney. It can promote 
the spleen, pancreas and mesenteric lymph nodes. The specific mechanism of $\mathrm{CU}$ in promoting immune function is not clear, which may be related to the composition of cell wall. CU, as an antigenic substance, can promote the development of immune organs. Shen et al. ${ }^{[13]}$ found that a certain proportion of yeast culture increased the concentration of intestinal IFN- $\gamma$ in weaned piglets, and there was no significant difference between the two groups. YSE may have a dose effect on the development of immune organs. Su et al. ${ }^{[26]}$ showed that YSE increased the immune organ index at low dose (100 mg / kg and $200 \mathrm{mg} /$ $\mathrm{kg}$ ), but decreased the immune organ index at high dose.

\section{Effects of CU and YSE on pH in gastrointestinal tract of weaned piglets}

Animal gastrointestinal tract is not only an important component of animal digestive system, but also a place for digestion and absorption of nutrients. Therefore, animal intestinal health is very important. The activity of digestive enzymes, the absorption of nutrients and the normal maintenance of intestinal immune function are affected by intestinal acidity ${ }^{[27]}$. Stress in weaned piglets caused an increase in adrenal corticosterone secretion and a decrease in the content of mucin secreted by digestive tract, resulting in a decrease in the level of intestinal organic acids and a decrease in the number of beneficial lactobacilli, while the decrease in the number of Lactobacillus further increased $\mathrm{pH}$, the increase of $\mathrm{pH}$ not only decreased the activity of intestinal digestive enzymes, but also conducive to the reproduction of Escherichia coli and other pathogens, resulting in diarrhea and other intestinal diseases ${ }^{[28-32]}$. It seriously harms the production performance of piglets ${ }^{[33,34]}$.

Our results showed that $\mathrm{CU}$ had little effect on gastrointestinal $\mathrm{pH}$ of piglets. YSE decreased the $\mathrm{pH}$, of stomach, colon, rectum and urine and only decreased the $\mathrm{pH}$ value of urine. $\mathrm{CU}$ and YSE cooperated with $\mathrm{CU}$ extract to reduce the $\mathrm{pH}$ of stomach, ileum, rectum and urine. In addition, oral yeast preparation decreased the $\mathrm{pH}$ value of intestinal segment, especially the effect of hindgut segment was more obvious [35-37]. Probiotic yeast can inhibit the growth of Escherichia coli, promote the proliferation of Bifidobacterium and Lactobacillus, and cause the increase of intestinal VFA content, while microbial fermentation is mainly in the hindgut, which may be the main reason for the change of $\mathrm{pH}$ in hindgut caused by yeast. Tian et al. ${ }^{[38]}$ pointed out that the YSE could reduce the $\mathrm{pH}$ value of rumen fluid of dairy cows. Although the mechanism of reducing ammonia concentration in YSE is controversial, a large number of studies have shown that YSE can inhibit the production of intestinal ammonia. Our results also show the effect of YSE in controlling ammonia gas from another aspect.

\section{Effects of CU and YSE on Plasma biochemical Indexes of weaned piglets}

Our results showed that the extract of $\mathrm{CU}$ could significantly improve the antioxidant capacity and the contents of plasma glucose, urea nitrogen and total cholesterol in weaned piglets. To a certain extent, plasma glucose and cholesterol reflect the glucose and fat metabolism of the body respectively $[39,40]$. Oztasan et al pointed out that the YSE significantly decreased the level of serum glucose in diabetic rats, 
but CU did not affect the level of plasma glucose ${ }^{[41]}$. Some studies have shown that the hypoglycemic function of YSE is related to its saponins ${ }^{[42-44]}$. However, in our study, YSE had no significant effect on plasma cholesterol content, which may be related to the intestinal regulation of cholesterol reabsorption and maintenance of cholesterol level. Blood urea concentration reflects the balance between protein metabolism and amino acids in animals. Our study showed that the addition of YSE to the diet decreased the content of plasma urea nitrogen, and there was a systematic tendency to reduce the content of plasma urea nitrogen between YSE and CU, which was consistent with the results of previous studies [45]. AST and ALT are indexes to evaluate liver function. Reis found that $750 \mathrm{mg} / \mathrm{kg}$ significantly increased the content of ALT in animals, and pointed out that high doses of YSE may have side effects on animals [46]. In this study, the addition amount of $120 \mathrm{mg} / \mathrm{kg}$, of CU and the content of ALT of CU were not significantly different from those of the control group, which indicated that this addition was safe for 28day-old weaned piglets. Even under normal physiological conditions, animal bodies produce free radicals. Excessive free radicals damage the structure and function of sugars, protein nucleic acids and other bioactive molecules and biofilms, resulting in functional and metabolic disorders. MDA is a metabolite of lipid peroxidation, indicating the state of biological stress ${ }^{[47]}$. SOD exists in a variety of tissues and organs to protect cells from superoxide free radicals, while CAT can hydrolyze hydrogen peroxide into non-toxic water and oxygen ${ }^{[48]}$. T-AOC is composed of key antioxidant enzymes and is a sign of the total antioxidant capacity of the body. In this study, dietary supplementation of YSE decreased plasma MDA concentration and increased plasma SOD concentration, which may be related to the scavenging effect of YSE on superoxide free radicals or preventing the formation of superoxides or peroxides ${ }^{[49]}$. Molavian pointed out that YSE scavenges hydrogen peroxide by increasing the level of CAT, which is consistent with the results of this study ${ }^{[50]}$. However, our study showed that CU increased T-SOD activity, CAT activity, TmurAOC and decreased MDA content, indicating that CU may have more potential in improving animal antioxidant capacity, which may be related to the ability of $\mathrm{CU}$ to synthesize glutathione ${ }^{[51,52]}$. Among all the experimental groups, CU and YSE synergistically improved the antioxidant capacity of weaned piglets, and the mixed group improved the antioxidant capacity of weaned piglets most obviously.

\section{Effects of CU and YSE on the morphology of ileal mucosa in weaned piglets}

Villus height, crypt depth and villus height / crypt depth are important indexes to evaluate the absorption function of small intestine. Our results showed that oral CU and diet supplemented with YSE promoted the development of ileal mucosa, and they synergistically increased villus height / crypt depth. The height of villi was significantly correlated with the number of cells. when the villi were long, the mature cells increased, and the contact area and absorption area with nutrients were enlarged, so the ability to absorb nutrients was enhanced ${ }^{[53]}$. The tubular structure formed by the sinking of the epithelium at the base of the villi to the lamina propria is the recess. Under the physiological state, the villous epithelial cells fall off normally. The exfoliated cells migrate, differentiate and produce mature villus cells from the base of the crypt to the villus end ${ }^{[54]}$. The depth of crypt becomes shallower, the maturation rate of epithelial cells increases, and the absorptive capacity of villi increases. Kong et al. ${ }^{[55]}$ added YSE to the diet of piglets to 
reduce the concentration of ammonia nitrogen in the contents of duodenum, jejunum, ileum, cecum and colon, improve the intestinal villus structure of piglets, increase the villus width of jejunum, increase the villus length and width of jejunum and the ratio of villus length to crypt depth of jejunum, but had no significant effect on the villus morphology of duodenum and jejunum. Yeast culture can be used as a foreign antigen to stimulate the development of intestinal tract. Some studies have shown that the addition of active yeast or yeast and its culture to the diet is beneficial to the development of intestinal mucosa and promote intestinal health ${ }^{[56,57]}$. In this study, it was found that YSE and CU increased the villus height of ileal mucosa, villus height / crypt depth, and decreased the crypt depth. In this study, the intestinal villi of piglets in the control group were shedding, while the situation in the experimental group was improved, indicating that YSE and CU can alleviate intestinal health problems caused by weaning stress. This is also one of the reasonable explanations for the reduction of diarrhea rate in the above study.

\section{Effects of CU and YSE on the levels of $\beta$-definsin-2 and Occludin in intestinal mucosa of weaned piglets}

Intestinal mucosa is the main barrier between the internal and external environment of the body, which can resist the invasion of harmful antigens through the role of mechanical, chemical, immune and microorganisms. Our study showed that oral CU and YSE increased the level of Occludin in jejunum and ileum and the level of $\beta$-definsin- 2 in jejunum, and increased the level of Occludin in jejunum and ileum together. The main mode of connection between intestinal mucosal epithelial cells is tight junction to maintain the integrity of the mechanical structure and function of the intestinal mucosal barrier. Tight junctions are composed of peripheral cytoplasmic proteins such as occludin, claudins, junction adhesion molecules and closed small ring proteins, in which occludin is a transmembrane protein related to the integrity of tight junctions. The antimicrobial peptides secreted by intestinal mucosa play an important role in resisting the invasion of pathogenic microorganisms. Defensin is one of the most deeply studied and widely existed antimicrobial peptides. On the one hand, it can be lower than the pathogenic microorganisms on the surface of intestinal epithelium. On the other hand, it is involved in immune regulation ${ }^{[58]}$. Studies have found that probiotics inhibit the translocation of pathogenic bacteria on the intestinal surface by maintaining the integrity of intestinal mucosa and reducing intestinal mucosal permeability, preventing toxins and harmful substances from entering the blood circulation, and pathogens can't further invade the body. in order to prevent the occurrence of disease ${ }^{[58]}$. Qamar et al. ${ }^{[59]}$ study found that oral administration of Saccharomyces cerevisiae induced specific immune response in mice infected with Clostridium, significantly increased the level of intestinal mucosal IgA, alleviated diarrhea and intestinal mucosal damage induced by endotoxin produced by Clostridium, indicating that probiotics such as yeast can enhance intestinal immune response and maintain intestinal health. In fact, there are few studies on the effects of $\mathrm{CU}$ and YSE on intestinal mucosal tight junction protein or $\beta$ defensin, but many studies have proved that they can enhance the immune function of animals. Our research confirms the above results to some extent. The possible mechanisms of probiotics protecting intestinal mucosal barrier are: maintaining the balance of intestinal flora, protecting microbial barrier, promoting mucus secretion, promoting the expression of tight junction protein, strengthening intestinal 
mucosal mechanical barrier, and stimulating intestinal mucosal immune response. Inhibition of intestinal

epithelial cell apoptosis ${ }^{[60]}$. In this study, YSE increased the levels of jejunal $\beta$-defensin and Occludin, which was beneficial to the health of weaned piglets. The effects of YSE and CU on the levels of intestinal $\beta$-defensin and Occludin can't be ignored in addition to the direct immunostimulatory effect on intestinal mucosal structural integrity. In addition, YSE and CU can promote the villus height of ileal mucosa and maintain the normal morphology of intestinal structure, which is essential for the normal secretion of antimicrobial peptides and related proteins. However, CU and YSE showed some differences in the effect on intestine. They both significantly increased the expression of Occludin and $\beta$-definsin- 2 in jejunal mucosa, but there was no significant difference in protein expression in ileum.

\section{Effects of CU and YSE on cecal microflora of weaned piglets}

The species richness of the sample can be reflected indirectly by drawing the dilution curve of the sample. when the curve tends to be smooth, it can be considered that the sequencing depth has basically covered all the species in the sample. Our research shows that the dilution curve height of the control group is lower than that of the other three experimental groups, suggesting that the species richness of the control group may be lower than that of the experimental group. Chao1 index and Shannon index curves tend to be saturated, indicating that the sequencing data are sufficient, most species have been detected, and more OTU can't be found by further increasing the sequencing data.

The Venn diagram is used to reflect the common and unique species among the samples. Our research showed that the four groups accounted for $84.53 \%$ of the total OTU, while the unique OTU control group, CU group, YSE group and CU + YSE group were $0.87 \%, 0.44 \%, 0.32 \%$ and $0.61 \%$, respectively, indicating that the experimental treatment had little effect on the core species in the intestinal tract of weaned piglets. The intestinal microflora of piglets has been changing since birth until a stable top community is formed ${ }^{[61]}$. The proportion of OTU shared by the four groups reached $84.63 \%$, which may be related to the stable top community gradually formed after weaning.

Our research showed that at the gate level, the cecal microorganisms of weaned piglets were mainly composed of Bacteroides and Firmicutes, which was consistent with the results of previous studies ${ }^{[62,}$ 63]. YSE and CU had no significant effect on the relative abundance of Bacteroides and Firmicutes bacteria, indicating that the addition of them had no significant effect on the dominant flora of weaned piglets. Proteobacteria are gram-negative bacteria, and many of them are pathogenic bacteria ${ }^{[64]}$. Our results showed that the YSE had no significant effect on the relative abundance of Proteus, but CU significantly reduced the relative abundance of Proteus, and the effect was better than that of $\mathrm{CU}$ alone. Acidobacteria are related to denitrification and nitrogen metabolism, and are greatly affected by nitrogen sources and $\mathrm{pH}^{[65]}$. Our results showed that the YSE decreased the relative abundance of the bacteria, which may be related to the decrease of ammonia in the intestine. Bacteroides can ferment glucose, fructose, galactose, lactose, sucrose and dextrin to produce acid and gas, resulting in a waste of energy. Our study showed that the increase of the relative abundance of Bacteroides was mainly caused by the 
interaction between YSE and CU, indicating that the interaction between YSE and CU was not ideal in improving the relative abundance of Bacteroides. Lachnospiraceae and Ruminococcaceae can ferment

cellulose to produce butyric acid to inhibit colitis, so we usually think that they are beneficial bacteria [66] Our study showed that oral $\mathrm{CU}$ and its culture increased the relative abundance of Lachnospiraceae and Ruminococcaceae in weaned piglets, which was beneficial to the maintenance of intestinal health. We believe that the effect of yeast and its culture on increasing beneficial bacteria and reducing harmful bacteria may be related to oligosaccharides and other active components in yeast culture. these active substances maintain gastrointestinal microecological balance, selectively promote the proliferation of beneficial flora and inhibit the reproduction of harmful bacteria.

In addition, our study showed that the abundance and diversity of cecal microflora in weaned piglets increased with the addition of YSE or CU, alone or in combination. The increase of microbial diversity is usually positively correlated with the stability of microflora and the ability to resist the invasion of pathogens. Our results showed that dietary supplementation of YSE and CU could improve the diversity of cecal microflora and improve the health level of weaned piglets. Beta diversity analysis can support this result. YSE and CU had a certain effect on the structure of intestinal microflora of weaned piglets, which changed the sample distance between the control group and the experimental group in Beta diversity analysis. With the addition of YSE or CU, the change of microflora developed in the same direction, which showed that the samples of the three experimental groups were gathered together. It is suggested that the effects of YSE and CU on intestinal microorganisms may be consistent.

\section{Conclusions}

This study provides evidence that YSE and CU are expected to replace antibiotics in the production of weaned piglets. Our study shows that YSE and CU can improve the growth performance of weaned piglets, reduce the diarrhea rate of weaned piglets, improve intestinal health, and increase the diversity and richness of cecal microflora of weaned piglets. At the same time, we provided the specific information of YSE and CU on the growth performance and healthy development of weaned piglets, thus providing information for the development of feed plans that can improve or resist the stress of weaning piglets. Future research in this field should focus on finding more perfect plant extracts to regulate the early development of weaned piglets, and the long term effect of offspring's productivity and health.

\section{Abbreviations}

YSE: Yucca Shidigera Extract; CU: Candida Utilis; CON: Control; RA: Relative abundance; GLU: Glucose; BUN: Blood urea nitrogen; T-SOD: Total superoxide dismutase; CAT: Catalase; T-CHO: Total cholesterol; AST: Aspartate aminotransferase; MDA: Transforming growth factor- $\beta ; A L T$ : Alanine transaminase; T-AOC: Total antioxidant capacity; ADG: Average daily gain; ADFI: Average daily feed intake.

\section{Declarations}


Acknowledgements

We thank Professor De Wu, Professor Guozhong Dong and Professor Yanchu Yao for their insightful suggestions on experimental design.

\section{Authors' contributions}

ZRT and ZGY formulated the hypothesis; ZRT and ZGY designed the experiment. YW conducted the animal experiment; YW, GZB and ZHS conducted laboratory analysis; TLH, GZB and WZS performed the data statistical analysis; ZGY, TLH and YW were responsible to write the first draft of the manuscript. ZRT, ZGY and TLH were responsible for the correction of the manuscript; ZRT and ZGY edit the last version of the manuscript. The manuscript was read and approved by all authors.

\section{Funding}

This study was funded in part by National Natural Science Foundation of China (31772610, 31902167), Chongqing Natural Science Foundation (Basic Research and Frontier Exploration Special Project) General Project (Grant No. cstc2019jcyj-msxmX0524), the National Science Foundation for Post-doctoral Scientists of China(Grant No. 2018M640895), Chongqing key innovation project for overseas students (cx2017024), National Key R\&D Program of China (2018YFD0501000), the the Special Funding for Postdoctoral Research Projects in Chongqing (Grant No. XMT 2081061).National Program on Key Basic Research Project of China (2013CB127303) and China Scholarship Council (201508505170).

\section{Availability of data and materials}

The datasets used and analyzed during the current study are available from the corresponding author on reasonable request.

\section{Ethics approval and consent to participate}

All animal procedures such as ethical and animal welfare issues wereapproved by the ethics committee of Southwest University.

\section{Consent for publication}

Not applicable.

\section{Competing interests}

The authors declare no conflict of interest.

\section{Author details}

Laboratory for Bio-feed and Molecular Nutrition, College of Animal Science and Technology, Southwest University, Tiansheng Road 2, Beibei District, Chongqing 400715, People's Republic of China. 


\section{References}

1. Alagawany MM, Farag MR, Dhama K, El-Hack MEA, Alam GM. Mechanisms and Beneficial Applicationsof Resveratrol as Feed Additive in Animaland Poultry Nutrition: A Review. Int J Pharmacol. 2015;11(3):213-221.

2. Alagawany MM, Farag MR, Dhama K. Nutritional and Biological Effects of Turmeric (Curcuma longa) Supplementation on Performance, Serum Biochemical Parameters and Oxidative Status of Broiler Chicks Exposed to Endosulfan in the Diets. Asian J Anim Vet Adv. 2015;10(2):86-96.

3. Alagawany M, El-Hack MEA. The effect of rosemary herb as a dietary supplement on performance, egg quality, serum biochemical parameters, and oxidative status in laying hens. J Anim Feed Sci. 2015;24(4): 341-347.

4. Dhama K, Latheef SK, Mani S, Samad HA, Karthik K, Tiwari R, et al. Multiple Beneficial Applications and Modes of Action of Herbs in Poultry Health and Production-A Review. Int J Pharmacol. 2015;11(3):152-176.

5. Sahoo SP, Kaur D, Sethi APS, Sharma A, Chandra M. Evaluation of Yucca schidigera extract as feed additive on performance of broiler chicks in winter season. Vet World. 2015;8(4):556-560.

6. Štochmal'ová A, Kadasi A, Alexa R, Grossman R, Sirotkin A. The effect of yucca on proliferation, apoptosis, and steroidogenesis of porcine ovarian granulosa cells. Potravinarstvo. 2014;8(1):87-91.

7. Wang JP, Kim IH. Effect of caprylic acid and Yucca schidigera extract on production performance, egg quality, blood characteristics, and excreta microflora in laying hens. Brit Poultry Sci. 2011;52(6);711-717.

8. Gebhardt JT, Woodworth JC, Tokach MD, Derouchey JM, Goodband RD, Loughmiller JA, et al. Determining the influence of chromium propionate and Yucca schidigera on growth performance and carcass composition of pigs housed in a commercial environment1. Trans Anim Sci. 2019;3(4):1275-1285.

9. Marek K, Katarzyna B, Javier JL, Anna MK, Joanna S. Metabolic Response of the Yeast Candida utilis During Enrichment in Selenium. Int J Mol Sci. 2020;21(15):5287-5304.

10. Anna ST, Tomasz H, Magorzata K, Bogusaw F. Dietary Supplementation of a Yeast-Whey Preparation for Weaned Piglets. Acta Vet. 2020;70(1):126-135.

11. Piyum AK, Justin M, Nhuan PN, Kevin BH, David GS. Conversion of deoxynivalenol to 3acetyldeoxynivalenol in barley-derived fuel ethanol co-products with yeast expressing trichothecene 3-0-acetyltransferases. Biotechnol Biofuels. 2011;4(1):26-38.

12. Wüthrich D, Irmler S, Berthoud H, Guggenbühl B, Eugster E, Bruggmann R. Conversion of Methionine to Cysteine in Lactobacillus paracasei Depends on the Highly Mobile cysK-ctl-cysE Gene Cluster. Front microbiol. 2018;9:2415-2425.

13. Shen YB,Piao XS,Kim SW,Wang L,Liu P,Yoon I, et al. Effects of yeast culture supplementation on growth performance, intestinal health, and immune response of nursery pigs. J Anim Sci. 2009;87(8):2614-2624. 
14. Zhang SH, Wu ZH, Heng JH, Song HQ, Tian M, Chen F, et al. Combined yeast culture and organic selenium supplementation during late gestation and lactation improve preweaning piglet performance by enhancing the antioxidant capacity and milk content in nutrient-restricted sows. Anim Nutr. 2020;6(2):160-167.

15. Zhaxi YP, Meng XQ, Wang WH, Wang L, Pu WX. A Yeast Probiotic, Improves Intestinal Mucosa Integrity and Immune Function in Weaned Piglets. Sci Rep. 2020; 10(1):4556-4568.

16. Lv LK, Zhang H, Liu ZY, Lei L, Feng Z, Zhang DD, et al. Comparative study of yeast selenium vs. sodium selenite on growth performance, nutrient digestibility, anti-inflammatory and anti-oxidative activity in weaned piglets challenged by Salmonella typhimurium. Innate Immun. 2020;26(4):258268.

17. Kiros TG,Derakhshani H,Pinloche E,D'Inca R,Marshall J,Auclair E, et al. Effect of live yeast Saccharomyces cerevisiae (Actisaf Sc 47) supplementation on the performance and hindgut microbiota composition of weanling pigs. Rep. 2018;8(1):5315-5327.

18. Khan SA, Zhang MZ, Liu L, Dong LH, Ma YX, Wei ZC, et al. Co-culture submerged fermentation by lactobacillus and yeast more effectively improved the profiles and bioaccessibility of phenolics in extruded brown rice than single-culture fermentation. Food Chem. 2020;326:126985-126992.

19. Bertsch A, Roy D, LaPointe G. Fermentation of Wheat Bran and Whey Permeate by Mono-Cultures of Lacticaseibacillus rhamnosus Strains and Co-culture With Yeast Enhances Bioactive Properties. Front Bioeng Biotech. 2020;8:956-963.

20. Sonya T, Slavka T, Konstantin G, Nikolai D, Luben A, Eddie P, et al. Origin of the extremely high elasticity of bulk emulsions, stabilized by Yucca Schidigera saponins. Food Chem. 2020;316:126365126390.

21. Piacente S, Pizza C, Oleszek W. Saponins and Phenolics of Yucca schidigera Roezl: Chemistry and Bioactivity. Phytochem Rev. 2005; 4(2-3):177-190.

22. Hong JW, Kim IH, Moon TH, Kwon OS, Lee SH, Kim YG. Effects of Yucca Extract and (or) Far Infrared Emitted Materials Supplementation on the Growth Performance, Serum Characteristics and Ammonia Production of Growing and Finishing Pigs. Asian Austral J Anim. 2001;14(9):1299-1303.

23. Colina JJ, Lewis AJ, Miller PS, Fischer RL. Dietary manipulation to reduce aerial ammonia concentrations in nursery pig facilities. J Anim Sci. 2001;79(12):3096-3103.

24. Ma MD, Wung LC, Kuo CC. Studies on deodorization of finishing pig excreta by adding Yucca schidigera extract (YSE) in different crude protein level diets. Taiwan Sugar. 2000, 25-30.

25. Sun H, Tang JW, Yao XH, Wu YF, Wang X, Feng J. Effects of dietary inclusion of fermented cottonseed meal on growth, cecal microbial population, small intestinal morphology, and digestive enzyme activity of broilers. Trop Anim Health Pro. 2013;45(4):987-993.

26. Su JL, Shi BL, Zhang PF, Sun DS, Li TY, Yan SM. Effects of Yucca Extract on Feed Efficiency, Immune and Antioxidative Functions in Broilers. Braz Arch Biol Technol. 2016;59:e16150035-e16150042.

27. Xia SD, Zha W,Li M, Zhang LB, Yang HS. Effects of dietary protein levels on the activity of the digestive enzyme of albino and normal Apostichopus japonicus (Selenka). Aquac Res. 
2018;49(3):1302-1309.

28. Kusumawaty D, Surtikanti HK,Hernawati, Tallei TE. Data on community structure and diversity of the intestinal bacteria in elver and fingerling stages of wild Indonesian shortfin eel (Anguilla bicolor bicolor). Data in Brief. 2020; 29:105299.

29. Wei B, Wang YK, Qiu WH, Wang SJ, Wang H. Discovery and mechanism of intestinal bacteria in enzymatic cleavage of C-C glycosidic bonds. Appl Microbiol Biot. 2020;104(5):1883-1890.

30. Zong X, Wang TH, Lu ZQ, Song DG,Zhao J,Wang YZ. Effects of Clostridium butyricum or in combination with Bacillus licheniformis on the growth performance, blood indexes, and intestinal barrier function of weanling piglets. Livest Sci. 2019. 220:137-142.

31. Fujita K, Sasaki Y, Kitahara K. Degradation of plant arabinogalactan proteins by intestinal bacteria: characteristics and functions of the enzymes involved. Appl microbiol Biot. 2019;103(18):7451 7457.

32. Yamamoto Y, Calvopina M, Izurieta R, Villacres I, Kawahara R, Sasaki M, et al. Colistin-resistant Escherichia coli with mcr genes in the livestock of rural small-scale farms in Ecuador. Bmc Res Notes. 2019;12(1):121-126.

33. John L, Scott S, Troy J, John O. Method and apparatus for treating water for use in improving the intestinal flora of livestock and poultry. US. 2002.

34. Jan LV. How Chicory Fructans Contribute to Zootechnical Performance and Well-Being in Livestock and Companion Animals. J Nutr.2007;137(11):2594S - 2597S.

35. Luiz GG, Gabriela MG, Hiam JM, Eduardo AB, Aleksandro SDS. Effects of yucca extract and organic chromium on growth performance and health of lactating lambs. Small Ruminant Res. 2020;91:106172-106178.

36. Oelschlager ML, Rasheed MSA, Smith BN, Rincker MJ, Dilger RN. Effects of Yucca schidigera-derived saponin supplementation during a mixed Eimeria challenge in broilers. Poultry Sci. 2019;98(8):32123222.

37. Theo R, Hanna S, Jessica T, Jochen W. Formation and stability of emulsions stabilised by Yucca saponin extract. Int J Food Sci Tech. 2018;53(6):1381 - 1388.

38. Tian LX, Shi BL, Fu XZ, Li TY, Zhao QL, Yue YX, et al. Effects of yucca extract on dairy cattle artificial ruminal fermentation parameters. Cereal \& Feed Industry. 2014;6(16):53-60.(In Chinese).

39. Cincotta AH. Medical use and composition for the treatment of lipid and glucose metabolism disorders . EP. 2012.

40. Beyene HB, Hamley S, Giles C, Huynh K, Smith A, Cinel M, et al. Mapping the Associations of the Plasma Lipidome With Insulin Resistance and Response to an Oral Glucose Tolerance Test. J Clin Endocr Metab. 2020;4(4):e1041-e1055.

41. Nuray 0 . The effects of Yucca schidigera on blood glucose and lipid levels in diabetic rats. African $\mathrm{J}$ Bioch Res. 2013; 7(9):179-183. 
42. Giovanni T. How treatments with endocrine and metabolic drugs influence pituitary cell function. Endocr Connect. 2020;9(2):14-27.

43. Lee KT, Sohn IC, Kim DH, Choi JW, Kwon SH, Park HJ. Hypoglycemic and hypolipidemic effects of tectorigenin and kaikasaponin III in the streptozotocin-induced diabetic rat and their antioxidant activity in vitro. Arch Pharm Res. 2000;23(5):461-466.

44. Olgun 0 , Alp ÖY. Effect of dietary supplementation of essential oils mixture on performance, eggshell quality, hatchability, and mineral excretion in quail breeders. Environ Sci Pollut Res. 2014;21(23):13434-13439.

45. Killeen GF, Connolly CR, Walsh GA, Duffy CF, Headon DR, Power RF. The effects of dietary supplementation with Yucca schidigera extract or fractions thereof on nitrogen metabolism and gastrointestinal fermentation processes in the rat. J Sci Food Agr. 2015;76(1):91-99.

46. Dos RJS, Zanger?nimo M G,Ogoshi RCS,Fran?a J, Costa AC,Almeida TN, et al. Inclusion of Yucca schidigera extract in diets with different protein levels for dogs. Anim Sci J. 2016;87(7):1019-1027.

47. TarekM,ShafeyHA,Al-BatshanAMS, Farhan. The effect of dietary flaxseed meal on liver and egg yolk fatty acid profiles, immune response and antioxidant status of laying hens. Ital J Anim Sci. 2015;14(3): 428-435.

48. KurutasEB. The importance of antioxidants which play the role in cellular response against oxidative/nitrosative stress: current state. Nutr J. 2015;15(1):71-92.

49. Enginar H, Avci G, Eryavuz A, Kaya E, Kucukkurt I, Fidan AF. Effect of Yucca schidigera extract on lipid pe- roxidation and antioxidant activity in rabbits exposed to $y$-radiation. Rev Méd Vét-Toulouse. 2006;157(8):415-419.

50. Molavian H, Madani TA, Kohandel M, Sivaloganathan S. The Synergetic Coupling among the Cellular Antioxidants Glutathione Peroxidase/Peroxiredoxin and Other Antioxidants and its Effect on the Concentration of H2O2. Sci Rep. 2015;5(1):13620-13627.

51. LI M, Chai JQ, SUN YF, GUO HJ, ZHANG W, LIU YJ, et al. The optimization of feed-grade beer yeast culture conditions. Southwest China Journal of Agricultural Sciences. 2008;(03):829-832.(In Chinese).

52. Espinosa C, Esteban MÁ. Effect of dietary supplementation with yeast Saccharomyces cerevisiae on skin, serum and liver of gilthead seabream (Sparus aurata L). J Fish Biol. 2020;97(3):869 - 881.

53. Lan YY, Zhang SP, Gong F, Lu CF, Lin G, Hu L. The mitochondrial DNA copy number of cumulus granulosa cells may be related to the maturity of oocyte cytoplasm. Hum Reprod. 2020;35(5):1120 1129.

54. Shonyela SM, Feng B, Yang WT, Yang GL, Wang CF. The regulatory effect of Lactobacillus rhamnosus $\mathrm{GG}$ on T lymphocyte and the development of intestinal villi in piglets of different periods. Amb Express. 2020; 10(1):76-86.

55. Kong JL, Guan WT, Wei JL Shu DP. Effects of Yucca extract on intestinal contents, digestive enzymes and intestinal villi morphology of piglets [C] /the 11th National Symposium on Animal Nutrition of Animal Nutrition Branch of Chinese Animal Husbandry and Veterinary Society. 2012.(In Chinese). 
56. Van CMC, Jansman AJM, Smidt H, Yoon I. Effects of yeast culture on performance, gut integrity, and blood cell composition of weanling pigs. J Anim Sci. 2007;85(11):3099-3109.

57. Bontempo V, Di GA, Savoini G, Dell'Orto V, Domeneghini C. Live yeast dietary supplementation acts upon intestinal morpho-functional aspects and growth in weanling piglets. Anim Feed Sci Tech. 2006;129(3-4):224-236.

58. Alexandre Y, Le BG, Boisramé GS, Le GF, Héry AG, Gouriou S, et al. Probiotics: A new way to fight bacterial pulmonary infections?. Med Maladies Infect. 2014;44(1):9-17.

59. Qamar A, Aboudola S, Warny M, Michetti P, Pothoulakis C, LaMont JT, et al. Saccharomyces boulardii stimulates intestinal immunoglobulin $A$ immune response to Clostridium difficile toxin $A$ in mice. Infect Immun. 2001;69(4):2762-2765.

60. lijima K, Koike T, Abe Y, Shimosegawa T. Cutoff Serum Pepsinogen Values for Predicting Gastric Acid Secretion Status. Tohoku J Exp Med. 2013;232(4):293-300.

61. Dethlefsen L, Huse S, Sogin ML, Relman DA. The pervasive effects of an antibiotic on the human gut microbiota, as revealed by deep 16S rRNA sequencing. PLoS Biol. 2008;6(11):e280-e291.

62. Isaacson R, Kim HB. The intestinal microbiome of the pig. Anim Health Res Rev. 2012;13(01): 100109.

63. Looft T, Allen HK, Cantarel BL, Levine UY, Bayles DO, Alt DP, Henrissat B, et al. Bacteria, phages and pigs: the effects of in-feed antibiotics on the microbiome at different gut locations. Isme J. 2014; 8(8):1566-1576.

64. Hawkey PM, Warren RE, Livermore DM, McNulty CAM, Enoch DA, Otter JA, et al. Treatment of infections caused by multidrug-resistant Gram-negative bacteria: report of the British Society for Antimicrobial Chemotherapy/Healthcare Infection Society/British Infection Association Joint Working Party. J Antimicrob Chemoth. 2018;73(3):2-78.

65. Liu CX, Dong YH, Hou LY, Deng N, Jiao RZ. Acidobacteria Community Responses to Nitrogen Dose and Form in Chinese Fir Plantations in Southern China. Curr Microbiol. 2017;74(3):396-403.

66. Barrios C, Beaumont M, Pallister Tess, Villar J, Goodrich JK, Clark, et al. Gut-microbiota-metabolite axis in early renal function decline. PloS one. 2015; 10(8):e0134311-e0134319.

\section{Figures}



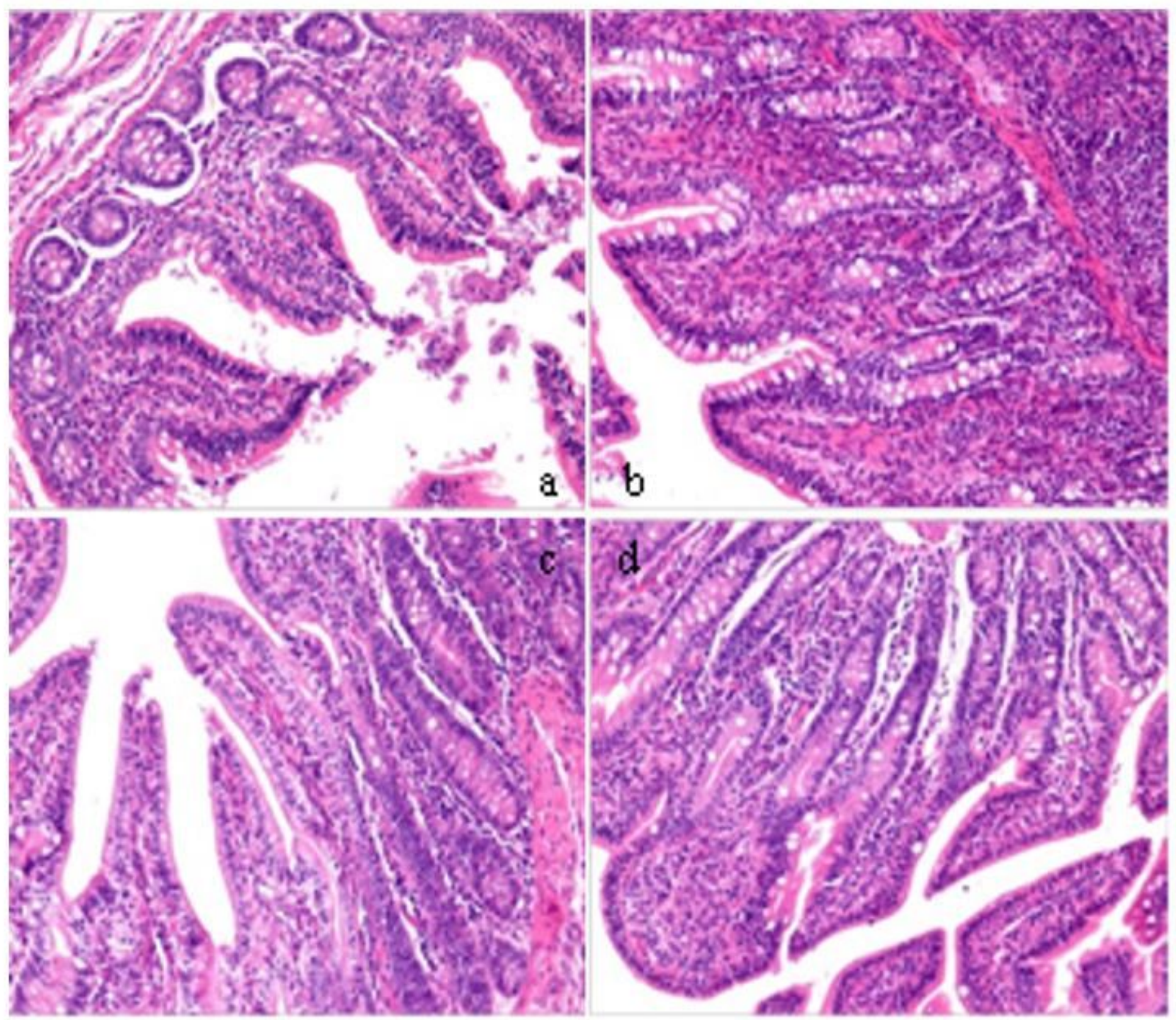

\section{Figure 1}

Morphology of ileum ( $\times 200)$ Note: a represents the control group, b represents CU group, c represents YSE group, d represents CU and YSE group.

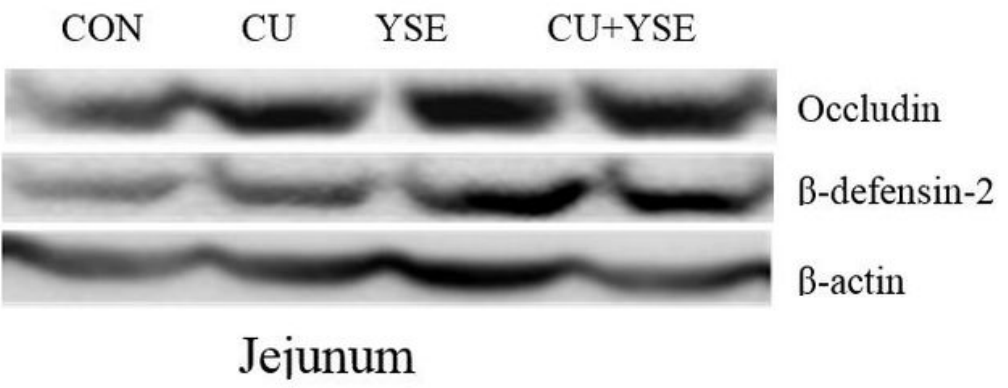

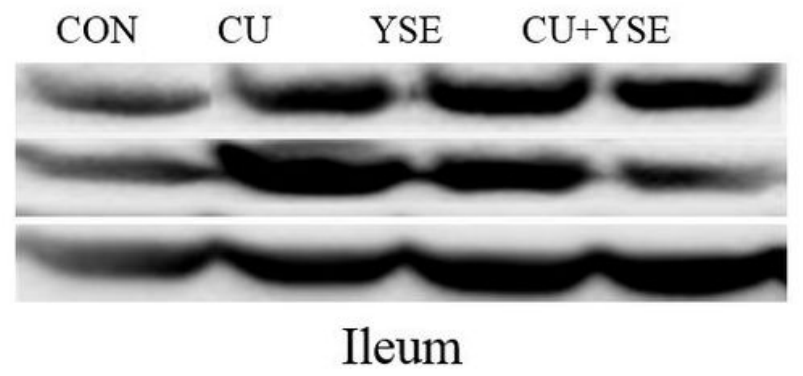


Figure 2

The levels of $\beta$-definsin-2, Occludin of jejunum and ileum Note: From left to right the stripes represent the control group, CU group, YSE group and CU and YSE group.
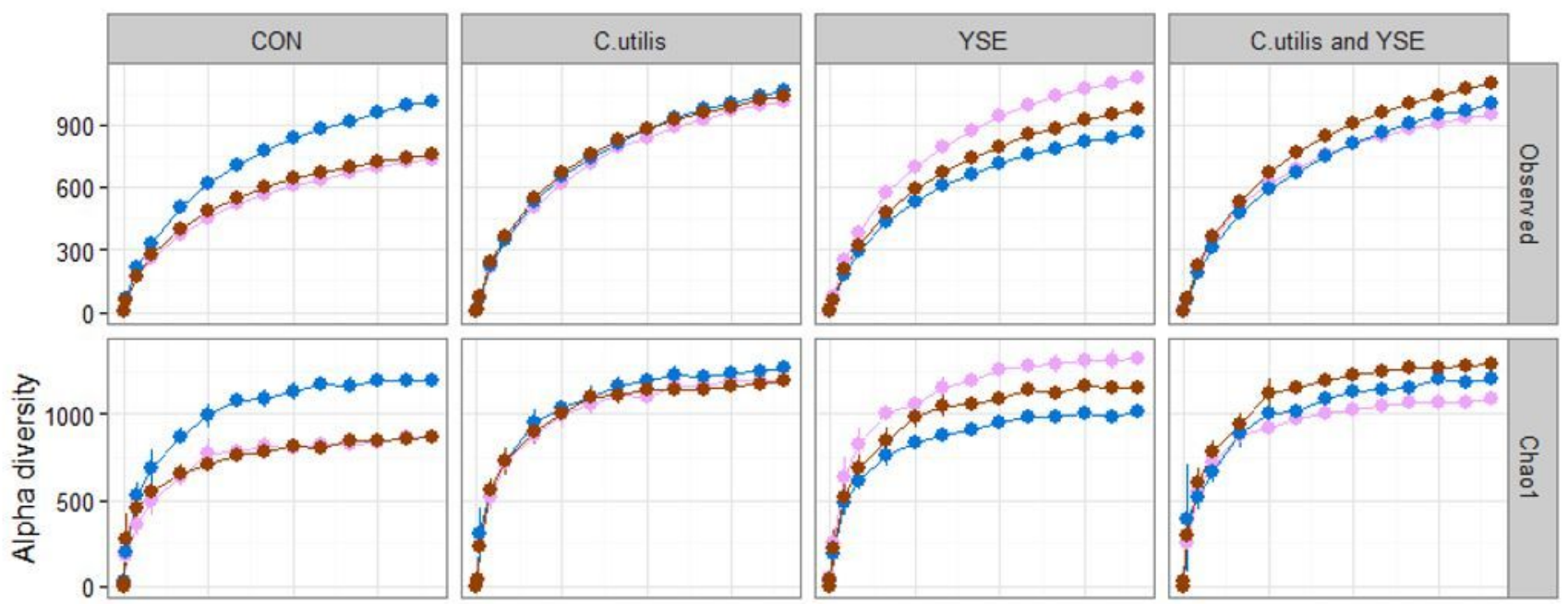

Replication
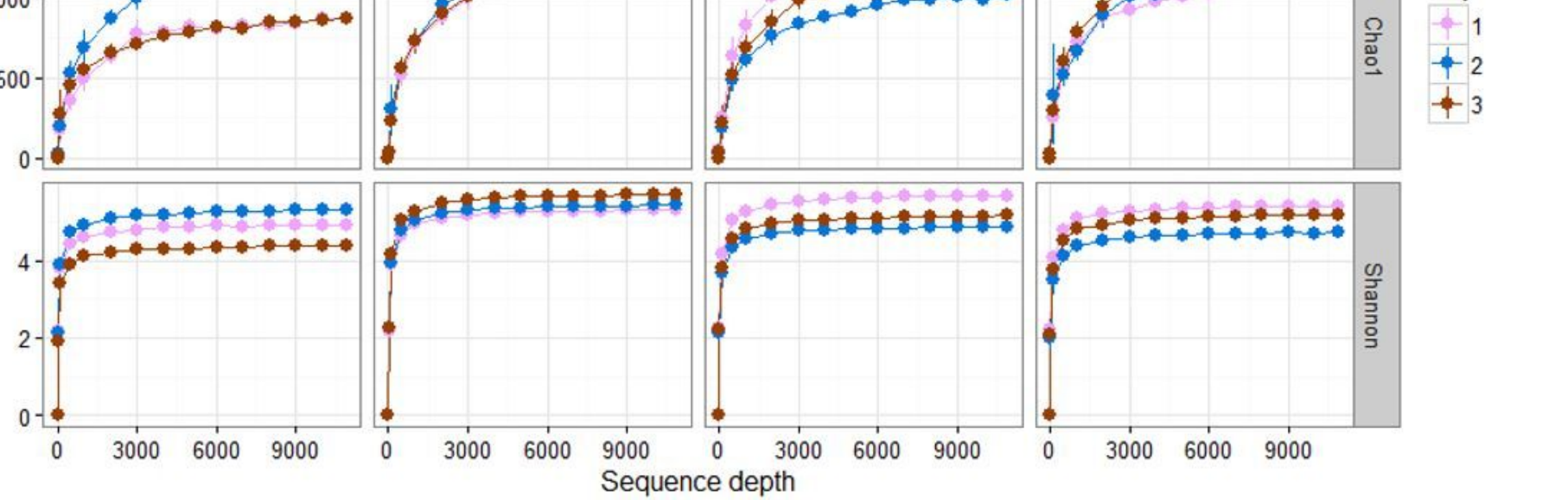

\section{Figure 3}

The rarefaction curve Note: CON is the control group, C. utilis is CU group, YSE is YSE group, C. utilis and YSE is the mixture of CU and YSE. 


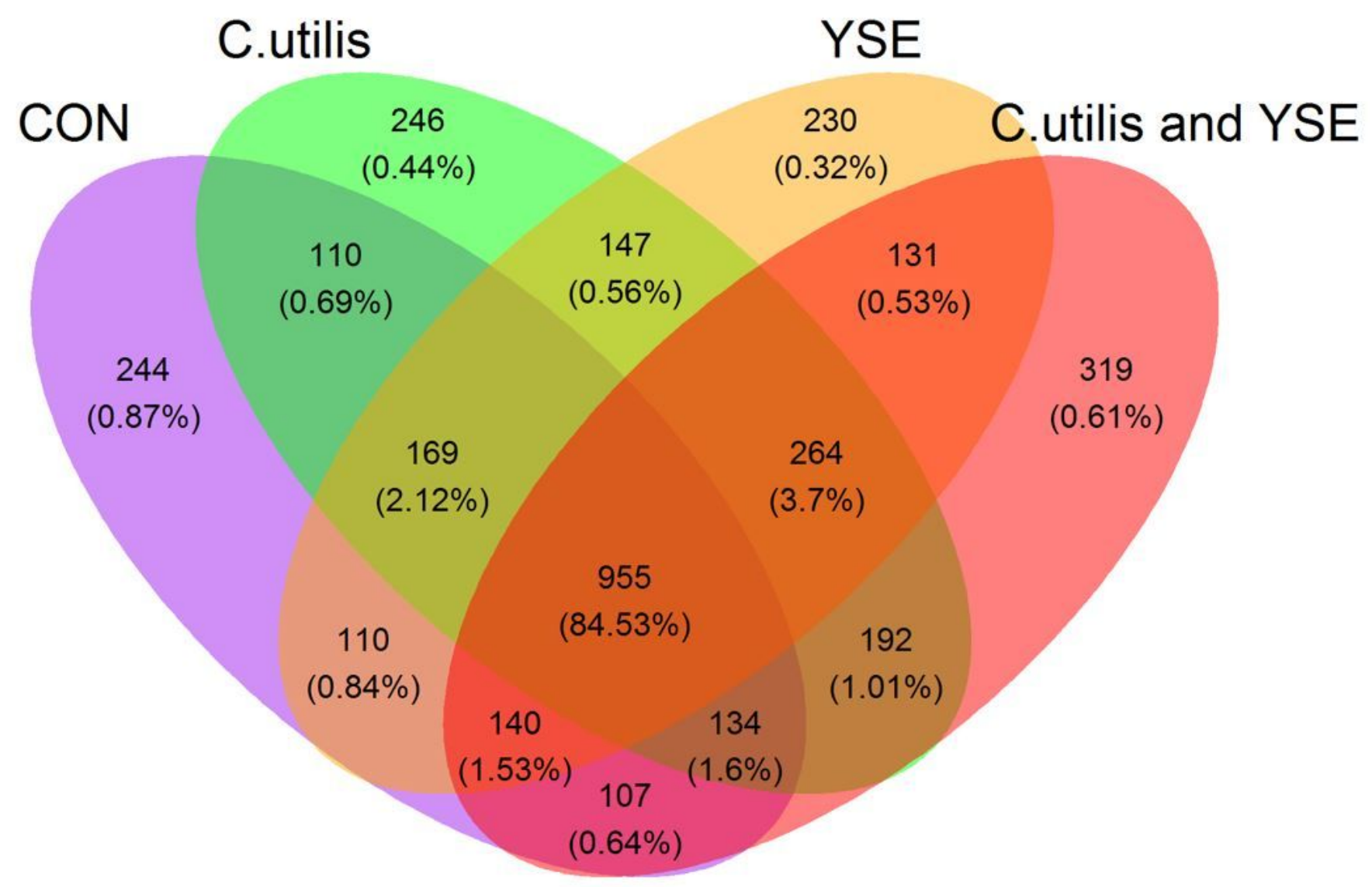

Figure 4

The Vene pot Note: CON is the control group, C. utilis is CU group, YSE is YSE group, C. utilis and YSE is the mixture of $\mathrm{CU}$ and YSE. 

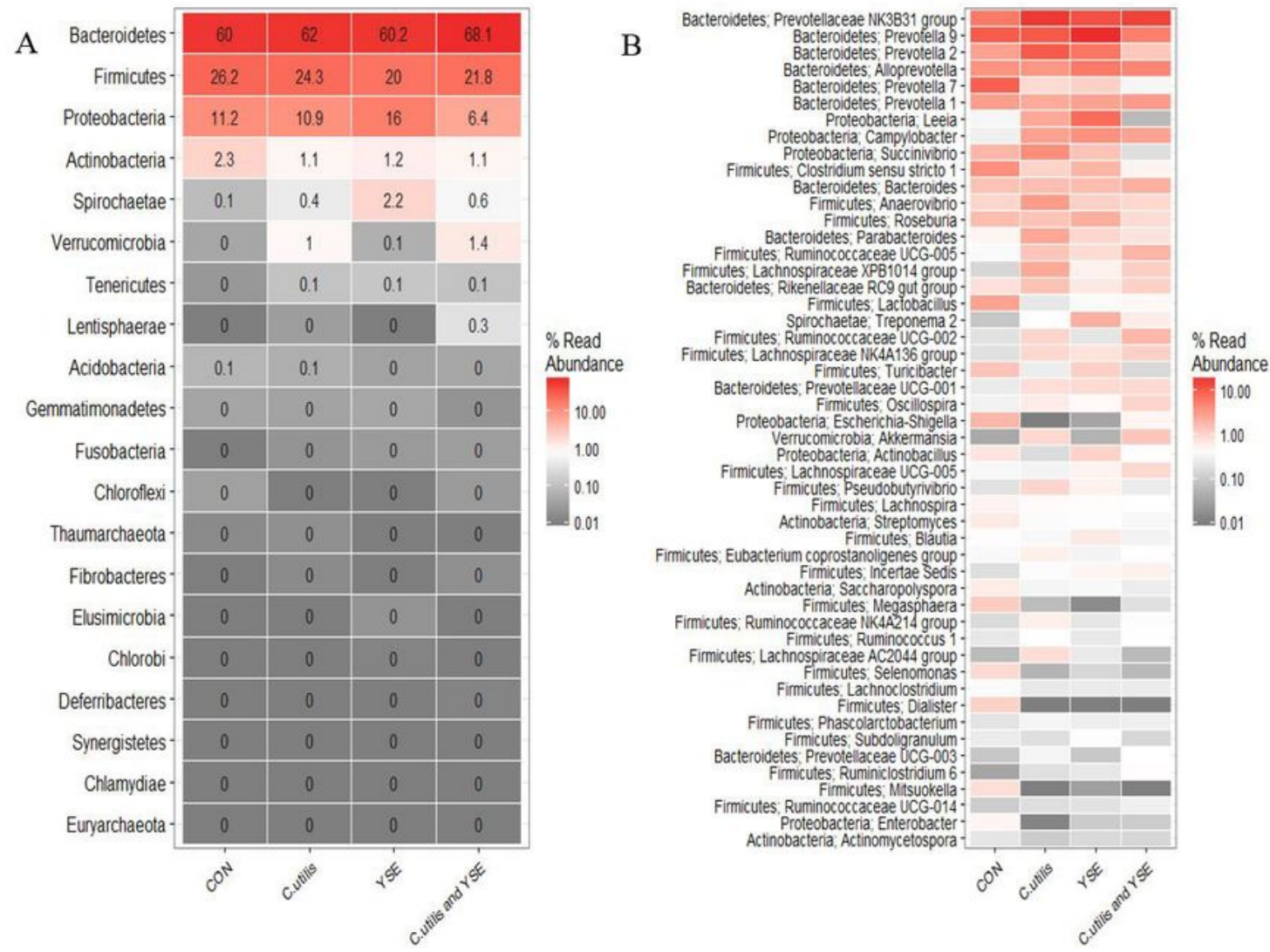

Fimicutes; Eubacterium coprostanoligenes group Actinobacteria Saccharaolyspora $\begin{aligned} & \text { Fimicutes: Megasphaera- }- \\ & \text { Firmicutes; Ruminococcaceae lik4A214 group }\end{aligned}$ Firmicutes, Firmicutes Ruminococcus 1 . Firmicutes, Lachnospiraceae AC2044 group. Firmicutes: Selenomionas
Firmicutes Lachnoclostridium Firmicutes; Lachnoclostridium -
Fimicutes: Dialister Firmicutes: Phascolarctobacterium -

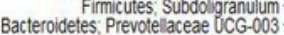
Fimicutes: Ruminiclostridium 6 Firmicutes: Ruminococcaceae UCG-014 Proteobacteria: Enterobacter Actinobacteria Actinomycetospora

\section{Abundance
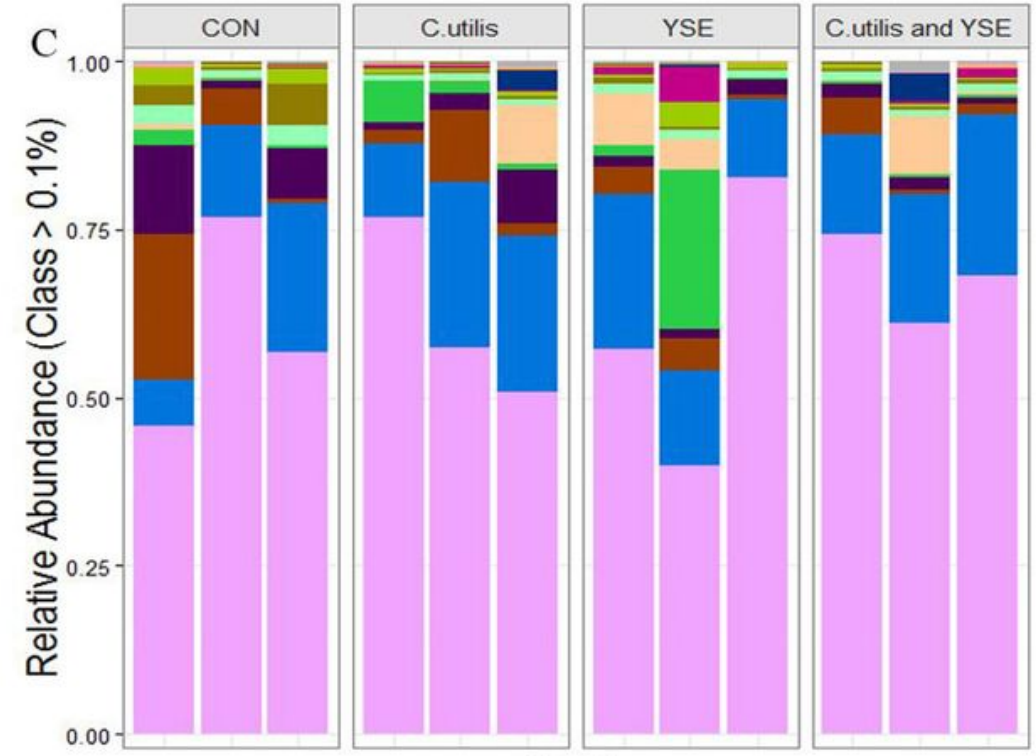

Class

Others

Alphaproteobacteria

Deltaproteobacteria

Cytophagia

Verrucomicrobiae

Spirochaetes

Erysipelotrichia

Bacilli

Actinobacteria

Epsilonproteobacteria

Betaproteobacteria

Negativicutes

Gammaproteobacteria

Clostridia

Bacteroidia

Sample

\section{Figure 5}

Abundance map at phylum, class and genus level Note: A represents the RA at phylum level, B at genus level and $\mathrm{C}$ at class level. Note: $\mathrm{CON}$ is the control group, $\mathrm{C}$. utilis is CU group, YSE is YSE group, $\mathrm{C}$. utilis and YSE is the mixture of CU and YSE. 

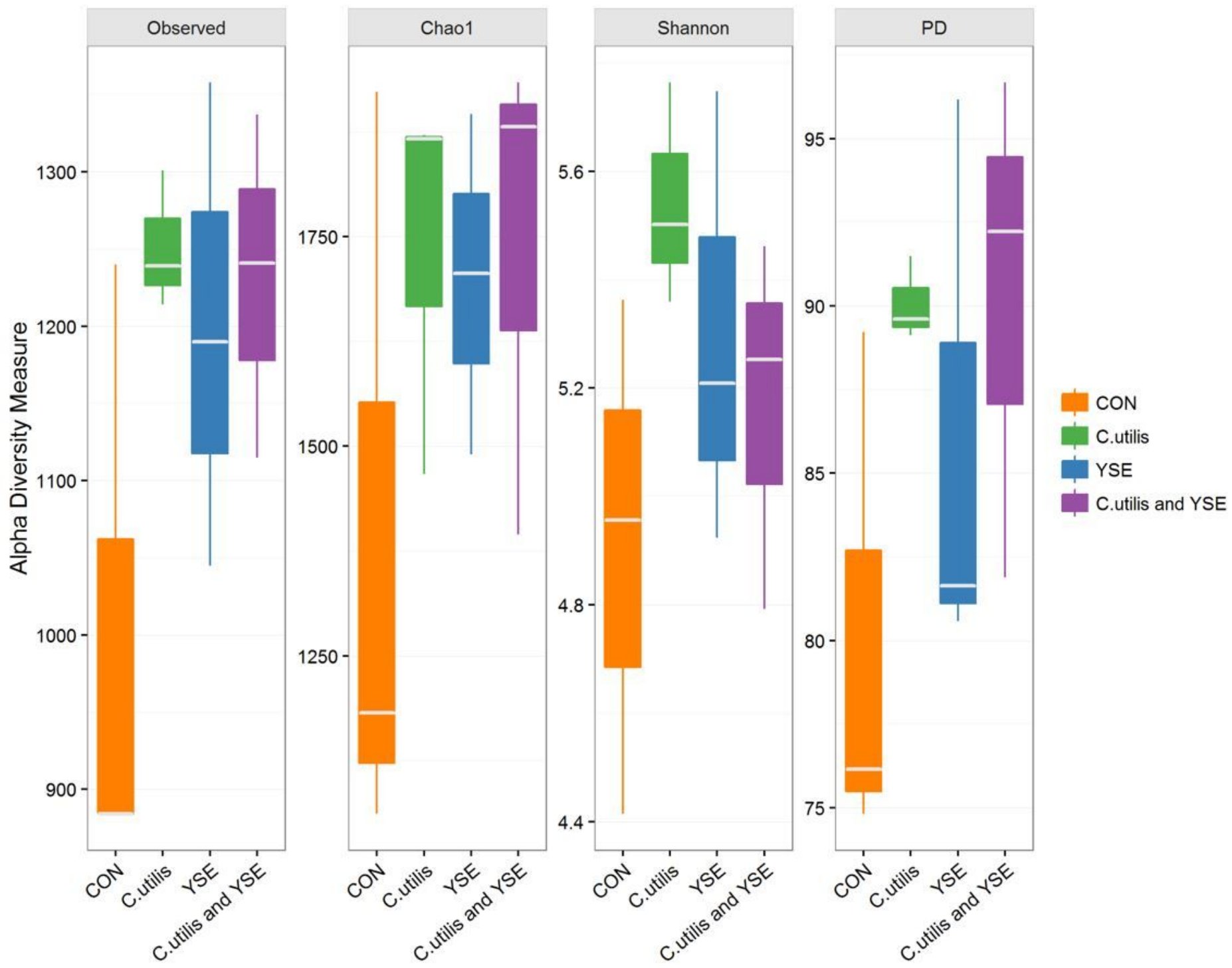

Figure 6

Alpha diversity analysis Note: CON is the control group, C. utilis is CU group, YSE is YSE group, C. utilis and YSE is the mixture of CU and YSE. 

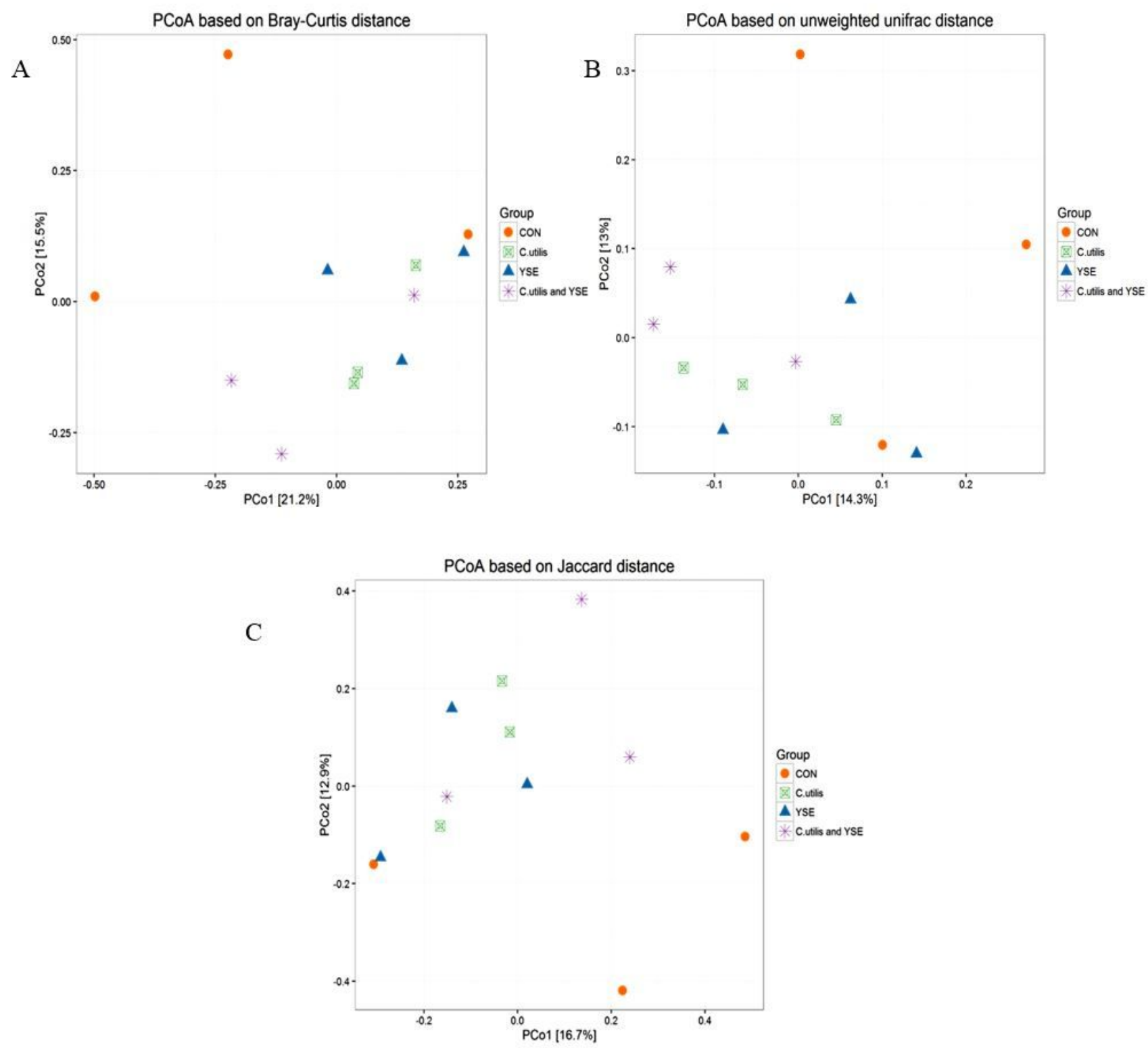

Figure 7

Principal Co-ordinates Analysis Note: A was PCoA analysis based on Bray-Curtis distance, B was PCoA analysis based on unweighted unifrac distance and $C$ was PCOA analysis based on Jaccard distance. Note: CON is the control group, $\mathrm{C}$. utilis is CU group, YSE is YSE group, C. utilis and YSE is the mixture of CU and YSE. 